\title{
PRESUPUESTOS DE UN MODELO RACIONAL DE LEGISLACIÓN PENAL
}

José Luis Díez Ripollés

Universidad de Málaga

\section{La crisis de la ley}

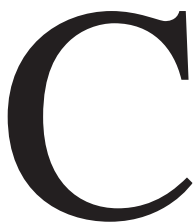

ualquier intento de profundizar en los contenidos de racionalidad que deberían resultar determinantes en todo proceder legislativo y en su resultado, la ley, ha de empezar por reconocer que la delimitación entre legislación y jurisdicción, entre lo que sea creación y aplicación del derecho, se mueve en estos momentos, tanto desde una perspectiva técnicojurídica como sociojurídica, sobre terreno poco firme. El protagonismo de la ley en la configuración del ordenamiento jurídico, rasgo esencial del derecho moderno ${ }^{1}$, está siendo seriamente cuestionado, hasta el punto de que se ha convertido en un lugar común hablar de la crisis de la ley. Con ello se querría expresar que la ley ha perdido la centralidad que venía ocupando en el sistema jurídico desde la instauración del estado de derecho liberal, como expresión de la voluntad general democráticamente expresada, reflejada en notas tales como su carácter único, originario, supremo e incondicional ${ }^{2}$. Las causas de ello son de muy diversa índole.

En primer lugar, la repercusión que en el papel de la ley y la legislación han tenido las sucesivas reestructuraciones del estado de derecho moderno: Su configuración ilustrada y revolucionaria, en la que la ley era el instrumento encargado de la racionalización social mediante el traslado de las leyes de la naturaleza al orden social, y que tiene su apogeo en el proceso codificador, es sustituida más tarde por un estado de derecho positivista. En él la ley, por un lado, alcanza el cénit de su importancia institucional, como producto de una voluntad contingente, no sometida a otros límites que la

${ }^{1}$ Sobre la ley y la legislación como elementos determinantes en el tránsito del derecho premoderno al derecho moderno, véanse, entre otros Ferrajoli. 909-912; Luhmann. 255-256.

2 Véase sobre el concepto de "imperio de la ley" en su dos sentidos, fuerte -aquí seguidoy débil, Hierro. 287-291. 
voluntad de los detentadores de la soberanía, pero, por otro, esa misma implícita arbitrariedad le priva de su estrecha vinculación a la razón, que se va desplazando paulatinamente de la creación a la aplicación del derecho; un buen reflejo de ello es el progresivo descuido en la ampliación o actualización de la empresa codificadora ${ }^{3}$. La aparición y consolidación del estado de derecho social consagra un activismo normativo en el que a la ya perdida racionalidad de la ley se añade su desbordamiento por reglamentos y normas de inferior rango, instrumentos con mejores prestaciones en la nueva sociedad intervencionista. De modo casi simultáneo, la aprobación de constituciones con abundantes contenidos sustanciales, ligados a la protección de derechos fundamentales o al establecimiento de principios orientadores de la acción política, constriñe el ámbito de la ley al espacio existente entre la actividad reglamentaria y el debido respeto a los principios constitucionales: Con la instauración de lo que ha sido llamado el estado de derecho constitucional la ley sufre, pues, un nuevo embate, en este caso derivado de la pérdida de status consecuente a su necesaria acomodación a las prescripciones normativas constitucionales ${ }^{4}$. Entre los últimos desarrollos del estado de derecho cabe aún mencionar los derivados del arraigo de la denominada sociedad del riesgo, ansiosa por prevenir peligros vinculados a actividades sociotecnológicas ambivalentes en su bondad: Ello, por un lado, demanda un intervencionismo administrativo superior al del estado social, lo que parece exigir una legislación imprecisa que permita la discrecionalidad administrativa $^{5} \mathrm{y}$, por otro lado, realza el protagonismo judicial, pues son finalmente los tribunales los que, ante la ausencia de conocimientos científicos seguros sobre las consecuencias de tales actividades tecnológicas, en principio lícitas, tienen la última palabra en cada caso sobre su procedencia ${ }^{6}$;

\footnotetext{
${ }^{3}$ Con todo, Ferrajoli. 210-213 destaca acertadamente el inicial papel consagrador del derecho racional natural que desempeña el positivismo jurídico hasta que, con la consolidación del estado de derecho liberal, pierde su referencia legitimadora externa.

${ }^{4}$ Véase una brillante descripción en Prieto Sanchís. 5-44. También Marcilla Córdoba. 94100. Un sugestivo análisis de esta evolución, guiado por la idea de que el modelo jerárquico que colocaba en primer plano la legislación se disuelve a lo largo de los siglos XIX y XX como consecuencia del terreno ganado por la jurisdicción a impulsos de la vigencia del principio de que el juez no puede abstenerse de tomar una decisión (principio de prohibición de denegación de justicia, o de inderogabilidad del juicio), en un contexto de producción legislativa masiva y poco consistente temporal y sustancialmente (objetivamente, en terminología funcionalista), en Luhmann. 277-280, 299-305, 310-319. Advierte de todos modos frente a periodizaciones groseras, influidas por el funcionalismo, Habermas. 519-527, por más que él mismo trabaje a fondo la contraposición entre estado de derecho liberal y estado de derecho social, con la pretensión de superarla (485 y ss.).

${ }^{5}$ Véase en este sentido, críticamente, Habermas. 519-527.

${ }^{6}$ Véase sobre la labor de los jueces como árbitros de disputas entre expertos, Beck. 250251.
} 
en cualquier caso la legislación pierde racionalidad o queda condicionada por el casuismo judicial.

A estas alturas, y en segundo lugar, se ha producido una notable transformación de las fuentes de creación del derecho. Ya no se trata sólo de constituciones materialmente enriquecidas, que privan a la legislación ordinaria de hecho, y no de un puro modo formal, de su carácter supremo e incondicional, sino de otro conjunto de fenómenos: En buena parte de Europa una cada vez más extensa legislación comunitaria se impone al legislador nacional pese a no proceder de un órgano legislativo, sin exigir refrendo parlamentario alguno y sin que cualesquiera teorías sobre distribución de competencias o delegaciones de soberanía puedan ocultar el hecho de que el legislador interno se encuentra cada vez más ante una situación de hechos consumados. En un plano distinto, el carácter único de la ley ha sufrido una alteración decisiva, tanto con la configuración del estado autonómico, que ha introducido una pluralidad de legisladores, como con la inserción de una jerarquía entre las leyes -estatutos de autonomía, leyes orgánicas, ordinarias-, disimulada con frecuencia mediante criterios de competencia. A ello debe añadirse la marcada relevancia que han adquirido las llamadas fuentes sociales del derecho, que terminan siendo ocasión para la aprobación de unas leyes previamente pactadas por los agentes sociales al margen del parlamento ${ }^{7}$.

En tercer lugar, el control de constitucionalidad de las leyes que ha traído consigo el estado de derecho constitucional, lejos de limitarse a colocar la ley bajo los designios de la norma fundamental, ha desencadenado un protagonismo de la jurisdicción frente a la legislación desconocido hasta ahora en el derecho moderno. No se trata simplemente de que los tribunales constitucionales, singularmente mediante la resolución de los recursos y cuestiones de inconstitucionalidad, corran el serio riesgo de suplantar al legislador, en especial cuando caen en la tentación de convertirse en legisladores positivos a través de sentencias que aportan determinados contenidos a la ley examinada ${ }^{8}$. La propia jurisdicción ordinaria, a cuenta de su capacidad para interponer cuestiones de inconstitucionalidad y de su obligación de realizar interpretaciones legales constitucionalmente conformes, ha asumido un papel que ha permitido decir a un destacado jurista que la vinculación del juez a la ley no es del todo cierta' ${ }^{9}$. El rico contenido de principios de las

\footnotetext{
${ }^{7}$ Véase en especial Hierro. 291-299. También Zapatero Gómez. 772-773; Prieto Sanchís. 28-31; Tudela Aranda. 105-107.

${ }^{8}$ A la problemática del control de la constitucionalidad de las leyes me volveré a referir infra.

${ }^{9}$ Ferrajoli. 914.
} 
modernas constituciones, y la necesidad de ponderar los en cada caso concurrentes, algo que se estima que no está al alcance de la perspectiva general y abstracta inherente a la legislación, ha originado que la aplicación judicial de cualquier ley se vea sometida a un previo análisis de su correspondencia en el caso concreto con ciertos principios, con independencia de su reconocimiento explícito o implícito en la norma legal correspondiente. Una conclusión negativa lleva a la inaplicación de las prescripciones de la ley mediante diversos mecanismos interpretativos ${ }^{10}$. Esta vinculación del juez a los principios y no a la ley se ve además potenciada por la reciente evolución de la teoría de la argumentación jurídica, pensada desde luego para la aplicación del derecho y no para su creación, y que, localizando la racionalidad jurídica en la jurisdicción, reserva para la legislación poco más que la legitimación derivada de la autoridad ${ }^{11}$.

Tampoco se ha de olvidar el aparentemente inamovible rol asumido por los juristas desde el surgimiento, en el marco del estado de derecho, del positivismo jurídico, momento en el que, a la búsqueda de una ilusoria neutralidad política y un pretendido incremento de la racionalidad, deciden limitar su estudio y aportaciones conceptuales a la aplicación del derecho. Se da por hecho, en consecuencia, que la creación del derecho es cosa de políticos, que no precisa de grandes elaboraciones conceptuales, en todo caso a desarrollar por filósofos del derecho, y que el jurista todo lo más debe aportar ocasionalmente cierta colaboración técnicojurídica. Las sucesivas transformaciones del estado de derecho no parecen haber modificado significativamente tal actitud ${ }^{12}$.

${ }^{10}$ Cuando no simplemente mediante su consciente ignorancia. En el ámbito penal, un buen ejemplo español es el tiempo que se tomó nuestro Tribunal supremo, en los años 80, antes de empezar a aplicar la modificación legal que se había producido de las reglas del error de prohibición en la reforma de 1983. Véase también sobre esa desobediencia a la ley, con ulteriores referencias, Cuerda Riezu. 81. Un ilustrativo ejemplo estadounidense, relativo a una administración de justicia aplicada en sus diferentes niveles a minimizar los desmesurados efectos punitivos de una ley surgida por iniciativa popular, se contiene en Zimring-Hawkins-Kamin. 125-133, 145-146, 218-220.

Es interesante igualmente constatar, entre otros fenómenos, la ambivalente utilización de la interpretación subjetiva, basada en la voluntad del legislador, que hacen los tribunales: $\mathrm{Si}$ bien formalmente se encuentra desacreditada como criterio de interpretación significativo, salta inopinadamente al primer plano cuando la argumentación judicial precisa apoyarse en ella para sacar determinadas conclusiones, para lo que no duda incluso en apoyarse en materiales prelegislativos. Véase al respecto Cuerda Riezu. 77-97.

11 Véanse Prieto Sanchís. 32-44, 52-66; Hierro. 296, 299-304; Ferrajoli. 914-922. Desde una perspectiva autopoiética, Luhmann. 235-238.

12 Véanse Calsamiglia. 162-167; Cuerda Riezu. 77; Marcilla Córdoba. 98-100; Zapatero Gómez. 769-770. 
Si a continuación nos preguntamos por la correspondencia de la evolución señalada en la ley penal, el cuadro que se nos muestra es uno matizado, que permite asumir en lo sustancial lo ya apuntado, pero con importantes precisiones.

En lo concerniente a la transformación histórica producida en el estado de derecho, no puede olvidarse que el derecho penal se ha mantenido durante los dos últimos siglos firmemente anclado en postulados básicos del estado de derecho liberal originario: Especialmente destacable es la persistencia de una profunda desconfianza hacia el uso por los poderes públicos de un instrumento jurídico tan poderoso como el derecho criminal, que sienta las bases para el mantenimiento de un conjunto de principios garantistas que permean toda la exigencia de responsabilidad penal, y que son objeto de periódicos intentos de desestabilización; a ello hay que añadir la continua pretensión desde la codificación novecentista, confirmada tras la superación en el siglo XX de los momentos más duros del positivismo jurídico, de identificar y clasificar de una manera racional los bienes básicos para asegurar la convivencia social y que habrán de ser justamente por eso objeto de protección jurídico-penal. El positivismo jurídico no socava, salvo periodos transitorios, la racionalidad de un derecho penal que sigue estando sustancialmente contenido en los códigos, por más que la asedia mediante un notable incremento de leyes especiales. Tampoco el estado de derecho social, que es además testigo del desarrollo de la teoría del bien jurídico como barrera frente a los abusos de un eventual renacimiento del positivismo voluntarista, cuestiona el status de una legislación penal que no se ve como factor de transformación social. Distinto es el caso del estado de derecho constitucional: Aunque ciertamente los preceptos constitucionales que tienen que ver con los principios de exigencia de responsabilidad y de legitimidad de la sanción se conforman con reforzar jerárquicamente contenidos normativos ya asentados en el derecho penal ${ }^{13}$, surgen fuertes tendencias a limitar los objetos de tutela del código a aquellos cuya valía tenga un explícito o implícito reconocimiento constitucional, así como a someterlos a ponderación con principios y valores constitucionales, todo lo cual tiene inmediatas repercusiones en el proceder legislativo y en la interpretación le$\mathrm{gal}^{14}$. A su vez, las exigencias de la sociedad del riesgo obligan a la ley penal a prestar atención a nuevos objetos de tutela colectivos, lo que fomenta sin duda una legislación mucho más imprecisa, con abundancia de tipos de peligro y frecuente uso de la técnica de la ley penal en blanco ${ }^{15}$.

\footnotetext{
13 Incluso se podría criticar a la constitución española el grado insuficiente en que lo hace.

${ }^{14}$ Por lo demás, no faltan intentos de refundar el derecho penal desde la constitución. Véase, entre los más destacados, Mir Puig.passim.

15 Véanse, entre otros, Silva Sánchez. (1999). 97-100.
} 
Por lo que se refiere a las transformaciones en las fuentes de creación del derecho, los efectos sobre la legislación penal son claramente menores que en otros sectores del ordenamiento jurídico: En este sentido resultan decisivos el respeto de las competencias penales nacionales por la legislación comunitaria, la competencia exclusiva del estado en materia penal en el nivel nacional y la indiscutida vigencia del principio de legalidad penal, reforzado por su apoyo constitucional y por una práctica parlamentaria que decide emplear la ley orgánica para legislar penalmente. No se puede olvidar, sin embargo, que no cesan de llegar instrumentos comunitarios de rango medio que obligan al legislador a acomodar el código penal a ciertas decisiones de órganos no legislativos de la Unión ${ }^{16}$ y que la legislación autonómica repercute indirectamente en los contenidos penales dada la frecuencia con que la técnica de la ley penal en blanco termina remitiendo a normas autonómicas ${ }^{17}$.

En cuanto al protagonismo de la jurisdicción frente a la legislación, se ha de reseñar ante todo que el tribunal constitucional se ha decidido, tras un buen tiempo de vacilaciones, a cuestionar la validez de ciertas decisiones legislativas penales con apoyo en algunos principios constitucionales, singularmente el de proporcionalidad ${ }^{18}$. Asimismo, la jurisdicción ordinaria hace ya tiempo que ha asumido un papel garantizador de la vigencia de ciertos principios de naturaleza garantista, lo que realiza por lo general mediante interpretaciones teleológicas que le llevan con frecuencia más allá de su función aplicadora del derecho ${ }^{19}$. A este respecto la jurisdicción penal dispone de una teoría de la argumentación, nucleada en torno a la teoría jurídica del delito, cuya profundidad y refinamiento le han dado una influencia tal que no resulta exagerado afirmar que la mayoría de las modificaciones legislativas relativas a los criterios de exigencia de responsabilidad penal han sido aplicadas previamente, por lo demás con escaso apoyo legal, en la jurisdicción ${ }^{20}$.

Tampoco faltan grandes procesos en los que es finalmente la jurisdicción la que marca la pauta entre diferentes opciones técnico-científicas El caso más llamativo sería el de la sentencia del aceite de colza. Véase STS. 23-4-92.

${ }^{16}$ Uno de los ejemplos más significativos es la reforma del código penal por LO. 11/99, como se reconoce en la exposición de motivos de la ley.

17 Véase el estado de la cuestión en Cerezo Mir.157.

18 Compárese su primera actitud, en Ss. del TC 65/86 FJ3, 19/88 FJ8, 150/91 FJ4b, 24/93 FJ5 , con las recientes Ss.TC 55/96 FFJJ 6 a 9, 161/97 FFJJ 8 a 11, 136/99 FFJJ 20 a 23, 27 a 30. Véase un sugestivo análisis de la jurisprudencia constitucional italiana, que muestra tendencias similares, en Palazzo. 721-727.

19 Véase un análisis de esa evolución en Silva Sánchez. (1999). 314-323. Véase también supra nota 10 .

${ }^{20}$ Piénsese en el delito continuado, los delitos de comisión por omisión, la consideración del error de prohibición... etc. Véanse al respecto mis afirmaciones en Díez Ripollés. (1997). 15. 
El confinamiento de los penalistas en la aplicación del derecho tiene explicaciones adicionales a las que ya hemos visto para los estudiosos del derecho en general. En primer lugar, la conocida separación de v. Liszt entre dogmática y política criminal llevó, sin que eso fuera la pretensión de su formulador, a un descuido generalizado de la segunda, objeto fácil de todo tipo de críticas sobre su acientificismo; la medida en que tal evolución se ha asentado la dan propuestas como la de Roxin que, tiempo más tarde, sólo se ve en condiciones de proponer aportaciones o directivas políticocriminales dentro de la propia teoría jurídica del delito, constituida en la materia por antonomasia de reflexión jurídicopenal ${ }^{21}$. En segundo lugar, la enorme potencia adquirida por la teoría jurídica del delito, cuyos ricos matices dan todo su juego en la aplicación del derecho, ejerce un efecto secante sobre cualesquiera esfuerzos tendentes a dotar de específicos contenidos de racionalidad a la creación del derecho. Por último, la habitual fundamentación del derecho penal a partir de los fines de la pena es un buen reflejo de un discurso legitimador de raíz, ahora sí, positivista centrado en la aplicación del derecho: Que la pena sea el centro de la argumentación presupone que la realidad jurídiconormativa del derecho penal ya existe, y que hay que justificar la aflicción que causa, a cuyos efectos surgen los principios limitadores de los objetos de tutela del derecho penal y los principios de la responsabilidad garantistas; un intento de legitimación que partiera de un derecho por crear empezaría justo al revés, identificando al derecho penal con la tutela de bienes jurídicos de la suficiente importancia como para que a continuación nos preguntáramos hasta dónde podemos llegar en su salvaguarda.

Sin embargo, esta evolución coincidente en cierta medida con otros sectores del ordenamiento jurídico no puede ocultar que la ley sigue gozando de una excelente salud en el derecho criminal. Una de las pruebas más visibles es el progresivo uso de la legislación simbólica, instrumento que recupera a la ley penal para labores de transformación o manipulación sociales, aunque sea a costa de ignorar principios básicos del derecho penal ${ }^{22}$. Otra son las reacciones antijudicializadoras y prolegisladoras que se han producido en ordenamientos jurídicos que fueron demasiado lejos en el protagonismo otorgado a la jurisdicción, como es el caso de Estados Unidos ${ }^{23}$.

${ }^{21}$ Véase Roxin. Passim. Un ilustrativo análisis de postura de v. Liszt y de la evolución a que dio lugar, se encuentra en García Pérez. 304-312, 355-356; cfr. también Cuerda Riezu. 77.

22 Véase al respecto Díez Ripollés. (2001). passim.

${ }^{23}$ En efecto, una aplicación y ejecución del derecho penal sentida por la opinión pública como excesivamente garantista para el delincuente condujo inicialmente a una notable restricción del arbitrio judicial y penitenciario mediante la reducción de la discrecionalidad judicial en la fijación de la pena concreta y de la discrecionalidad en las decisiones administrativas de sometimiento a prueba, más adelante dio lugar a las comisiones de imposición de penas, que 


\section{Las racionalidades legislativa y judicial}

En el trasfondo de todo lo hasta ahora visto hay una cuestión que no se puede aplazar más, y es la de si la legislación está en condiciones de alcanzar un nivel de racionalidad equiparable a la de la jurisdicción.

Tanto dentro de la sociología como de la filosofía del derecho, e incluso del derecho penal, existen voces que por diferentes vías destacan la imposibilidad de la legislación de alcanzar cotas de racionalidad en alguna medida equiparables a las de la jurisdicción.

Para la teoría sistémica autopoiética de Luhmann legislación y jurisdicción se encuentran insertas en una relación simétrica, sin $\operatorname{rangos}^{24}$, en la que la jurisdicción ocupa el centro del sistema jurídico y la legislación ${ }^{25}$ la periferia. La jurisdicción adquiere ese lugar central porque se le asigna la tarea de lograr en todo momento la consistencia, la coherencia, del sistema jurídico. Esa tarea encuentra su explícita expresión en el principio de prohibición de denegación de justicia, que obliga a los tribunales a decidir todo caso que se les plantee jurídicamente, con independencia de que exista una legislación aplicable. Esta ineludible obligación de decidir, aunque sea a costa de proceder a simplificaciones, es la que permite a la jurisdicción alcanzar su independencia política en el marco de la división de poderes, dota de contenido a la argumentación jurídica, y es su aportación al cierre operativo del sistema jurídico sobre sí mismo. Por su parte, la legislación se mueve en la periferia del sistema jurídico, en contacto con otros sistemas, singularmente el político, cuyas irritaciones recibe pero a las que no está obligada a responder, de modo que unas veces las atiende, procediendo a modificaciones jurídicas, y otras no. Es justamente esta ausencia de la obligación de decidir lo que le permite realizar su aportación al cierre operativo del sistema jurídico, en cuanto que lo hace autónomo frente a los otros sistemas de la sociedad. Por otro lado, la legislación es el lugar donde se transforma la política en derecho, satisfaciendo así otra importante misión, la de lograr el equilibrio temporal en el sistema social, un equilibrio que está ligado a la posibilidad del sistema político de activar la legislación cuando se

establecen de manera general escalas de pena en función de la concurrencia en los delitos de ciertas circunstancias, y en último término ha propiciado iniciativas legislativas, algunas populistas, que han eliminado o limitado drásticamente los marcos penales de los que los jueces pueden disponer. Véase Zimring-Hawkins-Kamin. 24-27, 110-117, 173-176, 182-187, $194-$ 201, 209-215, 217-218, 231-232, con un análisis teórico sobre el reparto de funciones entre legislativo y judicial ; Larrauri Pijoan. (1998).13-15.

${ }^{24}$ Frente a la relación jerárquica que fue habitual durante mucho tiempo, en la que la jurisdicción se limitaba a aplicar deductivamente la ley.

25 Junto con la actividad contractual privada, que ahora vamos a dejar fuera de consideración. 
ve irritado por otros sistemas. Ni una ni otra tarea legislativa pasan por el aseguramiento de la consistencia del sistema jurídico, muy al contrario, en ellas prima la variedad, la contingencia ${ }^{26}$ : Por una parte, las leyes pretenden ser ambiguas, con cláusulas indeterminadas o de ponderación, para permitir a los tribunales llegar a soluciones casuistas adecuadas, por otra, la legislación está especialmente dispuesta a atender las irritaciones del sistema político, pues corre pocos riesgos, ya que las leyes se orientan siempre sobre consecuencias presumidas, en buena medida desconocidas, sin olvidar que la mera aprobación de la ley ya tiene en sí efectos políticos ${ }^{27}$. En consecuencia, señala Luhmann, en la medida en que el mantenimiento de la consistencia es una tarea de la jurisdicción ${ }^{28}$ sólo en ella puede buscarse la racionalidad jurídica; así se explica por qué los repetidos intentos de los juristas por alojar la racionalidad del derecho en la actividad legislativa, construyendo una ciencia de la legislación, siempre han fracasado ${ }^{29}$.

Prieto Sanchís ha sostenido que la consolidación del estado de derecho constitucional ha convertido a la jurisdicción y su racionalidad en la protagonista del devenir jurídico. La existencia de constituciones ricas en principios a respetar ha originado, por un lado, que la legislación deba aproximar su operar al propio de la jurisdicción: La tradicional racionalidad legislati-

${ }^{26}$ La mejor prueba de que la legislación se opone al decidir consistente reside en que toda modificación jurídica contradice el principio de igualdad en la medida en que trata casos iguales de modo distinto según se produzcan antes o después de la entrada en vigor de la ley.

${ }^{27}$ Luhmann destaca el incremento de frecuencia de las modificaciones legales, lo que él denomina la temporalización de la validez de las normas, debido a la especial sensibilidad cognitiva, es decir, irritabilidad frente a otros sistemas, de las leyes en la sociedad contemporánea.

${ }^{28}$ Con todo, estima que la jurisdicción dispone de una fórmula de contingencia, de variedad, que le permite también a ella realizar modificaciones jurídicas. Esta formula es la de la justicia, que pretende asegurar el trato igual de los casos iguales y el desigual de los desiguales. Es, sin duda, la vía por la que en la concepción de Luhmann se destaca la idea del actuar judicial ligado a principios y no a la ley.

29 Véase Luhmann. 229-233, 235-238, 277-280, 299-305, 310-328, 426-429, 557-561, 563-564.

La exposición realizada de las opiniones luhmannianas recoge las últimas conclusiones a las que llegó sobre este tema tras el giro autopoiético de la teoría sistémica. Sus concepciones anteriores mantenían igualmente la atribución de la contingencia a la legislación y la consistencia a la jurisdicción y apuntaban ya a esa relación simétrica y no jerárquica entre ambas, sin embargo mantenía una neta distinción entre programas finales propios de la legislación, y condicionales propios de la jurisdicción, que desapareció en sus últimos escritos a favor de la exclusiva presencia de los segundos -véase Luhmann. 195-204-, destacaba el enfoque cognitivo y proclive al aprendizaje de la legislación, ahora no desaparecido pero muy limitado debido al cierre autopoiético del sistema jurídico, y defendía la racionalidad del conjunto del sistema así como la interdependencia entre la racionalidad jurisdiccional y la legislativa. Véase un magnífico resumen de su postura sobre el tema que nos ocupa hasta 1990, en Giménez Alcover. 227, 242-242, 247, 256-257, 267-269, 274-280, 285, 324. 
va orientada a fines debe ceder frente a una racionalidad sistemática, atenta a verificar la acomodación de la ley a principios superiores. Por otro lado, esos principios exigen su ponderación en cada caso, algo que la ley con sus previsiones generales no está en condiciones de realizar, a diferencia de la jurisdicción. En ese contexto, frente a los esfuerzos por rehabilitar a la ley como núcleo de la actividad jurídica, lo que procede es acomodarla a la nueva distribución de competencias que postula el estado de derecho constitucional, en la que su racionalidad queda en un segundo plano ${ }^{30}$.

Para Ferrajoli, mientras la legislación está sometida a todo tipo de intereses y a criterios representativos, la jurisdicción se configura como una actividad cognoscitiva, encaminada a la búsqueda de la verdad procesal. En ese dato encuentra la jurisdicción su legitimación dentro de la división de poderes, y mediante ese proceder está en condiciones de garantizar las libertades de los ciudadanos en el caso concreto, sustrayéndolos a las decisiones de las mayorías. Esa primacía de la racionalidad jurisdiccional frente a la legislativa se ve atemperada de dos modos: Por un lado, por el dato cierto de que la búsqueda de la verdad encuentra límites en la práctica judicial, que deben ser rellenados por la discrecionalidad, lo que hace que la legitimación del poder judicial sea siempre parcial e incompleta. Por otro lado, porque la jurisdicción, por mucho que las actuales constituciones permitan buscar la garantía de los derechos fundamentales más allá de la letra de la ley, no puede prescindir de la legitimidad formal derivada de la vinculación del juez a la ley; ello hace que precise de unas leyes mínimamente racionales, y de una ciencia de la legislación que se ocupe de asegurar tal $\cos ^{31}$.

Distinto es el enfoque ilustrado de Habermas, quien fundamenta la legitimidad de las normas jurídicas en la racionalidad del proceso legislativo que ha llevado a su creación, proceso que configura un discurso políticojurídico en el que están presentes contenidos muy diversos: Morales, éticosociales, compromisos entre intereses y aspectos pragmáticos ${ }^{32}$. En todo caso, cualquier discurso jurídico, de creación o de aplicación del derecho, está condicionado por las exigencias comunicacionales del sistema jurídico, que pretenden compensar el hecho de la imposibilidad de acceder a un discurso racional pleno. En este contexto, hay que reconocer que los discursos aplicadores del derecho, al ocuparse de casos concretos, pueden presumir de

\footnotetext{
${ }^{30}$ Véase Prieto Sanchís. 31-45, 61-66.

31 Véase Ferrajoli. 553-559, 591-594, 960-963. Una visión pesimista sobre la capacidad de la legislación para garantizar los principios garantistas penales se aprecia también en Silva Sánchez. 309, 312-315, 323.

${ }^{32} \mathrm{El}$ contenido de la racionalidad legislativa se verá en otro lugar infra.
} 
una mayor racionalidad que los discursos creadores del derecho. Sin embargo, los discursos aplicadores no pueden sustituir a los creadores del derecho, que son los encargados de fundamentar las normas, hasta el punto de que los tribunales se han de limitar a redescubrir las razones con las que el legislador ha legitimado sus decisiones -sin duda con la pretensión de lograr una decisión coherente con todo el ordenamiento en el caso aislado-, pero sin que puedan disponer de aquellas. Cuando no se pueda evitar que la jurisdicción decida en las zonas grises entre la aplicación y la creación del derecho, las razones propias de la aplicación deberán complementarse con las inherentes a la creación y, de todos modos, se precisará de una legitimidad adicional vinculada a la concordancia de la decisión con la opinión pública jurídica ${ }^{33}$.

Tampoco un importante sector de la filosofía del derecho española está dispuesto a dejar el campo libre a la racionalidad jurisdiccional. Para Atienza la racionalidad judicial es inalcanzable sin una previa racionalidad legislativa, y tampoco tiene sentido hablar de argumentación jurídica si ella no contiene dentro de sí la argumentación que se desarrolla en la elaboración del derecho. Por lo demás, la racionalidad en ambos momentos operativos del derecho ha de responder a exigencias similares, sin que ello suponga desconocer las diferencias existentes. Se ha de tratar, en cualquier caso, de una racionalidad fuerte, que no se limite a la coherencia lógico-formal sino que se ocupe también de los fines a obtener y de principios morales ${ }^{34}$.

Por mi parte, considero que la preferencia otorgada a la racionalidad jurisdiccional frente a la legislativa no está justificada.

En primer lugar, porque se basa en una caracterización inexacta de la actividad legislativa: La crítica funcionalista autopoiética de que carece de consistencia, así como de que no es más que una actividad simbólica al servicio del sistema político, ignora a mi juicio sus propios presupuestos metodológicos, ya que el mismo cierre autopoiético del sistema jurídico obliga a éste a asegurar que la legislación satisfaga sus exigencias intrasistémicas de coherencia, no siendo posible que la legislación, por mucho que se

\footnotetext{
${ }^{33}$ Concepto que estima más amplio que la cultura de los expertos jurídicos, y a la que estima capaz de someter a discusión pública las decisiones judiciales.

También estima Habermas que las crecientes funciones directivas de la administración le llevan en ocasiones a realizar discursos fundamentadores o aplicadores del derecho, además de los suyos propios meramente ejecutores, y en tales casos su legitimación precisa, además de los controles parlamentarios y judiciales, los derivados de la intervención directa o representada de los afectados. Véase sobre todo lo anterior Habermas. 285-291, 317-324, 340-348, 528533.

${ }^{34}$ Véase Atienza. 60-61, 74-91, 95-100. En un sentido semejante, Marcilla Córdoba. 100106, con ulteriores referencias doctrinales. Véanse también, entre otros, Hierro. 295, 306-307; Zapatero Gómez. 777-783; Calsamiglia. 169-178; Cuerda Riezu. 80-81.
} 
encuentre en la periferia del sistema jurídico, se limite a reflejar las irritaciones del sistema político localizado en su ambiente. Las afirmaciones que destacan las dificultades de la legislación para acceder a una racionalidad sistemática pasan por alto que la obtención de un ordenamiento jurídico libre de contradicciones es siempre una meta de todo proceder legislativo ${ }^{35}$, que se sustancia a través de técnicas tan acreditadas como la jerarquía de las fuentes legales, las remisiones o las cláusulas derogatorias y supletorias. En cuanto a sus problemas para realizar ponderaciones entre principios, no se alcanza a ver por qué la legislación no puede proceder a tales ponderaciones en el plano general que le es propio ${ }^{36}$, con soluciones que podrán ser aplicadas sin problemas por la jurisdicción en la mayor parte de los casos. Por lo demás, sólo desde un rechazo a la principialización de la actividad jurisdiccional se puede hacer a la legislación el reproche de que su orientación a fines y a las consecuencias, dada la imprevisibilidad de su producción ${ }^{37}$, le imposibilita un tratamiento racional de la realidad; la consideración de las consecuencias de su decisión es justamente una de las características fundamentales de una jurisdicción que busca su racionalidad con desapego de la ley.

En segundo lugar, porque una racionalidad jurídica centrada en una jurisdicción intérprete de la constitución da lugar a un modelo indebidamente estático de estado de derecho: Ante todo, porque origina una continua presión para incrementar la atribución de contenidos normativos a una decisión general constituyente localizada en el pasado, con la consecuente relativización de decisiones generales contemporáneas, en mejores condiciones para acomodarse a las actuales necesidades sociales. Por lo demás, la capacidad de adaptación de una jurisdicción con un ámbito interpretativo constitucionalmente expandido no puede contrarrestar la evidencia de la mayor fuerza socialmente transformadora de la legislación, aun sometida a una constitución materialmente enriquecida. En realidad, detrás de esa proyección a primer plano de la jurisdicción late una idea equivocada, la de que la relación entre jurisdicción y legislación es una de suma cero, de modo que todo lo que se otorgue a la jurisdicción va en detrimento de la legislación y viceversa; una constitución normativa, sin embargo, lo que plantea es una elevación del nivel de racionalidad tanto legislativa como jurisdiccional, para satisfacer así las pretensiones teleológicas, éticas y morales de la

\footnotetext{
35 Véase también Atienza. 60-61.

36 Por lo demás, convendría no olvidar que, salvando las debidas distancias, la actividad legislativa está acostumbrada a desenvolverse en un marco de compromisos entre intereses diversos, en donde se procura, como en la ponderación de principios, garantizar en lo posible una coexistencia de los diversos contenidos..

${ }^{37}$ No por casualidad, ésa es una de las críticas fundamentales de Luhmann a la actividad de los tribunales constitucionales. Véase infra.
} 
norma fundamental. Tampoco puede dejarse de mencionar que tal dinámica minusvalora uno de los fundamentos de todo estado de derecho, su estructuración en torno a la ley como expresión de la voluntad general democráticamente expresada $^{38}$, imperio de la ley que se ve socavado por la aparentemente mayor trascendencia de decisiones particulares. Que eso es algo contraintuitivo se percibe fácilmente si apreciamos el reiterado uso de la técnica legislativa en nuestra sociedad, que sería superficialmente desacreditada si dijéramos que es mayoritariamente inconsistente y simbólica.

En tercer lugar, el mantenimiento de un principio que nadie cuestiona frontalmente, la vinculación del juez a la ley, hace que la racionalidad jurisdiccional tenga como presupuesto un nivel apreciable de racionalidad legislativa. De hecho, en el improbable caso de que los tribunales prescindieran de la legislación ordinaria y operaran sólo a tenor de la constitución, precisarían que ésta fuera una norma con un significativo nivel de racionalidad... legislativa. En efecto, hay un importante sustrato de racionalidad común a legislación y jurisdicción, que es el que permite su interrelación, por más que el énfasis en unos contenidos u otros pueda ser bastante diferente ${ }^{39}$.

Las peculiaridades del ordenamiento penal abogan igualmente por el debido aprecio de la racionalidad legislativa. Al menor desgaste que la idea del imperio de la ley ha sufrido en este sector jurídico ${ }^{40}$ habría que agregar que, pese a todos los problemas, persiste una aspiración de racionalidad global de los contenidos legislativos penales, que se refleja formalmente en el mantenimiento de un único cuerpo legal casi omnicomprensivo, el código, y materialmente en la pretensión de lograr un catálogo de bienes jurídicos protegidos coherente, y de mantener un único sistema de responsabilidad penal y de sanciones, por más que no falten propuestas, hasta ahora inatendidas, para alterar esa situación ${ }^{41}$.

Ahora bien, pienso que sólo la instrumentación de un adecuado control de la racionalidad legislativa permitirá el aseguramiento de ésta frente a las tendencias siempre presentes de irracionalismo voluntarista. A tales efectos se ha de asumir que el punto de referencia de ese control es un conjunto normativo cualificado, la constitución y el bloque de constitucionalidad, y

\footnotetext{
38 Véase asimismo Hierro.287-291, 304-307.

${ }^{39}$ En cualquier caso, hablar de una racionalidad cognoscitiva en la jurisdicción, como hace Ferrajoli, es una pretensión en exceso ambiciosa

40 Véase supra apartado 1.

${ }^{41}$ Piénsese en especial en las propuestas para crear un derecho penal de intervención, o uno más cercano al derecho administrativo, que no deberían de respetar del mismo modo las exigencias de lesividad y responsabilidad habituales. Véase, entre nosotros, Silva Sánchez. (1999). 115-127, y una buena referencia crítica a esas tendencias en Martinez-Buján. passim; Schünemann. 15-36.
} 
el órgano de control uno jurisdiccional, el tribunal constitucional. Pero esto nos introduce en otro tema problemático.

\section{La legitimación del control de constitucionalidad de las leyes}

No es éste desde luego el lugar adecuado para ocuparse a fondo de este trascendente tema, ni tampoco estoy seguro de estar en condiciones de hacerlo, pero creo que puede resultar ilustrativo, de cara al ulterior análisis del contenido de la racionalidad de la ley penal, valorar ciertas opiniones autorizadas de la sociología del derecho y la filosofía jurídicopenal.

En efecto, pese a la diferente actitud ante la legislación y su racionalidad que mantienen, tanto Habermas como Luhmann se muestran muy cautos respecto al papel que les corresponde a los tribunales constitucionales en el control de las leyes.

Para el primero, la atribución de tal competencia origina dos riesgos de especial entidad: Por un lado, pone en peligro la división de poderes, en cuanto que tales tribunales, bajo las condiciones de un estado de derecho social, no pueden limitarse a considerar programas sólo condicionales, sino que se ven obligados a ocuparse de programas finales, de directivas políticas orientadas al futuro, asumiendo así competencias legislativas para las que carecen de legitimidad democrática ${ }^{42}$. Por otro, suelen transformar las constituciones en un orden de valores en lugar de considerarlas como un sistema de reglas estructuradas de acuerdo a principios, lo que les lleva a convertirse en una instancia autoritaria que ya no se ocupa de identificar normas obligatorias sino que asume la tarea de optimizar todos los valores, sin contradecir ninguno ${ }^{43}$. Su existencia sólo puede justificarse si ese control de las leyes se concibe como un autocontrol del legislador delegado en el tribunal $^{44}$, lo que exigiría una designación parlamentaria de los magistrados, la declarada adopción de una perspectiva de análisis propia de un legislador, y la renuncia del tribunal a considerarse poseedor de una racionalidad superior a la de aquél. A su vez, el control de constitucionalidad debería limitarse estrictamente a asegurar que se respetan los presupuestos comunicacionales y los condicionamientos procedimentales del proceder legislativo, tanto en el ámbito parlamentario como en el de la opinión pública, sin que

\footnotetext{
${ }^{42}$ Habermas considera que también bajo el paradigma del estado de derecho liberal se altera la división de poderes, en la medida que tales tribunales se ven obligados a acudir a legitimaciones externas.

43 Critica Habermas también que el punto de partida de la argumentación jurídicoconstitucional sean unos preceptos tan abstractos y cargados ideológicamente como los derechos fundamentales, en lugar de normas aisladas y concretas.

${ }^{44}$ Aun cuando Habermas se lamenta de que no se haya valorado con el suficiente detenimiento la alternativa de crear una segunda instancia legislativa.
} 
pueda aportar valores, y limitando las aportaciones de principios a aquellos inherentes al procedimiento democrático ${ }^{45}$.

Para el segundo, los tribunales constitucionales se configuran como elementos esenciales del acoplamiento estructural que, a través de las constituciones modernas, se lleva a cabo entre el sistema político y el jurídico. Su legitimidad como controladores de la constitucionalidad de las leyes se basa en que sean capaces de mantener ese acoplamiento sin desdibujar los límites entre ambos sistemas; eso implica que no deben salir del ámbito de los programas condicionales, de forma que cuando el control de constitucionalidad les lleve a considerar programas finales, éstos sólo han de verse desde la perspectiva de cuáles sean las condiciones que deben darse para que tal programa final pueda aplicarse, debiendo dejar fuera de consideración toda reflexión sobre su oportunidad, coste, proporcionalidad, utilidad...etc ${ }^{46}$. Sólo de este modo su decisión sobre la constitucionalidad o no de la ley se podrá ver como una decisión jurídica. Sin embargo, es habitual que los tribunales constitucionales se impliquen en el desarrollo de directrices políticas, viéndose a sí mismos como agentes controladores de la ponderación de valores, con intervenciones arbitrarias vinculadas a valoraciones sociales consideradas plausibles. Eso hacer saltar por los aires la delimitación entre los sistemas jurídico y político ${ }^{47}$.

Actitud muy distinta se deduce de la concepción por Ferrajoli del Estado de derecho constitucional como aquél que ha incorporado en su ordenamiento como criterios de legitimación interna gran parte de las habituales fuentes de legitimación externa. Ello se logra mediante la integración en el sistema de criterios de legitimidad jurídica sustancial (validez) junto a los ya conocidos criterios de legitimidad jurídica formal (vigencia), y una estructuración jerárquica, con la constitución en la cúspide, de los diferentes niveles normativos y decisionales, en virtud de la cual cada nivel debe respetar los criterios de validez y vigencia suministrados por el nivel superior y asegurar a su vez la efectividad de sus prescripciones o decisiones en el nivel inferior. A partir de ese entrelazamiento puede caracterizar al Estado de derecho moderno como aquel ordenamiento cuya legitimación externa

\footnotetext{
45 Véase Habermas. 294-348, 528-533.

${ }^{46}$ Como es sabido, un programa condicional se distingue de un programa final en que en el primero se fijan las condiciones necesarias para producir ciertos efectos, de manera que si se dan aquellas deben producirse éstos, mientras que en el segundo se identifican los efectos que se quieren producir y se acepta una relativamente amplia e imprecisa variedad de acciones mediante las que se puedan lograr aquellos. Así, los primeros se estructuran en torno a las condiciones, y los segundos en torno a las metas. Véase una síntesis de la concepción de Luhmann al respecto en Giménez. Alcover. 218-219.

47 Véase Luhmann. 229-233, 468-481, 557-561.
} 
reside en que es posible la legitimación interna del poder. De tal entendimiento es fácil colegir ${ }^{48}$ unos tribunales constitucionales legitimados para controlar plenamente unas leyes ordinarias cuyos contenidos están ya predeterminados por unas constituciones normativas que han asumido ávidamente criterios de legitimación externa, entre ellos, programas políticos de acción $^{49}$.

A mi entender, planteamientos como el de Ferrajoli cuestionan la división de poderes, en detrimento del legislativo. En efecto, dejan sin margen real de actuación al legislador y le privan de este modo de su función mediadora entre política y derecho, función que no le convierte, como pudiera superficialmente pensarse, en un mero agente del sistema político, contrapuesto a una jurisdicción que reflejaría los contenidos del sistema jurídico. Muy al contrario, el legislativo opera dentro del sistema jurídico, pero abierto a unos criterios de legitimación externa que un estado de derecho como el que propone Ferrajoli habría fosilizado para siempre en la constitución. Es cierto, sin embargo, que un control de constitucionalidad de las leyes resulta imprescindible para poner coto a un legislador arbitrario. Este cerco difícilmente se podrá erigir dentro de su propio ámbito de competencias, por ejemplo, mediante la creación de una segunda instancia legislativa, del mismo modo que el último control de la arbitrariedad de la jurisdicción no es el tribunal supremo sino una modificación legislativa ${ }^{50}$.

Pero el freno a la arbitrariedad legislativa no se logra sin más desplazando tal riesgo a los tribunales constitucionales, los cuales manejan un material normativo, la constitución, especialmente proclive a favorecer decisiones sobrepasadoras de la división de poderes ${ }^{51}$. Es preciso asegurar un metacontrol de los citados tribunales mediante una estricta delimitación de sus competencias de control legislativo. A este respecto, la propuesta de Habermas de constreñir tal control a la comprobación de que se respetan las exigencias comunicacionales y procedimentales de un proceder legislativo deliberativo apunta en la dirección correcta. Se podría formular también, siguiendo a Hierro, en el sentido de que mientras el legislador debe partir de

\footnotetext{
${ }^{48}$ Al margen de la, ya aludida supra, vinculación laxa de los jueces a la ley ordinaria, atentos en todo momento a las normas constitucionales.

${ }^{49}$ Véase Ferrajoli. 347-362, 898-907, 912-922. La conclusión final del texto es mía, sin que Ferrajoli la formule explícitamente.

${ }^{50}$ Alude a esta alternativa en manos del legislador Cuerda Riezu. 82-83.

${ }^{51}$ No se puede negar, sin embargo, que la mera existencia de un control de constitucionalidad de las leyes mediante tribunales constitucionales aporta de forma inmediata ciertas ventajas. Entre ellas, la que deriva de que es sustancialmente preferible una declaración de inconstitucionalidad de una ley que un continuo e impredecible goteo de forzadas interpretaciones legales conformes con la constitución, procedentes de la jurisdicción ordinaria.
} 
una concepción fuerte de la ley, que recoja con la mayor fidelidad posible la voluntad general, el tribunal encargado de su control se ha de conformar con una concepción débil, que simplemente aspire a verificar que los presupuestos para su formulación se han cumplido ${ }^{52}$.

Ahora bien, esos presupuestos no se limitan al respeto de las consabidas formalidades competenciales y secuenciales previstas en la constitución y en las actuales leyes del bloque de constitucionalidad. La comprobación de que en su elaboración se ha producido una adecuada participación ciudadana y de que se han averiguado cuáles sean las opiniones sociales ${ }^{53}$ sienta las bases de la racionalidad ética ${ }^{54}$; la verificación de que se han realizado los correspondientes estudios previos sobre la realidad social a incidir, los objetivos a perseguir, los medios de que se dispone y las posibles consecuencias de la decisión legislativa debiera asegurar un grado aceptable de racionalidad teleológica y pragmática; la coherencia con el resto del ordenamiento jurídico promoverá una racionalidad lógico-formal... En suma, la concurrencia de tales presupuestos hará que la ley supere el control de constitucionalidad por respetar un limitado nivel de racionalidad, sin que en ningún momento eso prejuzgue el contenido de la decisión legal finalmente adoptada ni su racionalidad socialmente exigible ${ }^{55}$.

Sin embargo, resultaría temerario dejar en manos de las posibilidades interpretativas que ofrecen los preceptos constitucionales la plena explicitación de las exigencias comunicacionales y procedimentales a controlar por el tribunal constitucional. Dada la vaguedad de la mayoría de las normas constitucionales a las que habría que acudir, se reeditaría el peligro de arbitrariedad de la jurisdicción constitucional. Lo pertinente es reformular, dentro del bloque de constitucionalidad, las normas que regulan el procedimiento de elaboración de leyes, de modo que, sin perder sus referencias constitucionales, se dé lugar a un notable enriquecimiento de sus exigencias.

En cualquier caso, la limitación de toda esa normativa a los requisitos de lo que hemos llamado una concepción débil de la ley originará que el legislador siga teniendo bajo su responsabilidad, como no puede ser de otra manera, el contenido sustancial de la actividad legislativa y que en este sentido, más allá del respeto que debe a la constitución, sólo esté sometido al

\footnotetext{
52 Véase Hierro. 288-291, 304-307.

53 Sobre la ineludible atención a los contenidos de la opinión pública y la sociedad civil, véase Habermas. supra

54 Sobre las diferentes tipos de racionalidad, véase Atienza. infra.

55 Si utilizáramos la terminología funcionalista, se trataría de que el tribunal constitucional no se saliera del ámbito de los programas condicionales, de que realizara lo que Luhmann denomina en su abstracto lenguaje una recondicionalización de los programas finales del legislador. Véase Luhmann. supra.
} 
control electoral derivado del funcionamiento democrático de la sociedad. Podríamos decir, volviendo a utilizar un símil jurisdiccional, que el control constitucional a lo único que aspira es a que motive bien sus leyes.

Una ciencia de la legislación, de todos modos, no tiene por qué elegir entre convertirse en auxiliar de la jurisdicción constitucional, o del legislador en la plenitud de sus funciones. A ambos debe procurar ser útil profundizando en las singularidades de la racionalidad legislativa y aportando instrumentos para su mejora a todos los niveles.

\section{Los contenidos de la racionalidad legislativa penal}

4.1. Es ya hora de comenzar a dotar de contenido a la racionalidad legislativa. Antes de iniciar una aproximación general a ella, que identifique sus pautas de referencia o niveles fundamentales, es preciso realizar dos aclaraciones. La primera es que las reflexiones que siguen se formulan pensando sobre todo en la racionalidad legislativa penal, objeto de este trabajo, por más que se tiene la impresión de que buena parte de las afirmaciones que siguen serían aplicables, mutatis mutandi, a otros sectores del ordenamiento jurídico.

La segunda es que no podemos postergar más la adopción de un determinado concepto de racionalidad, concepto cuyo contenido hemos podido dar hasta ahora por sobreentendido en la medida en que nos limitábamos a contraponer de una manera general las prestaciones de que eran capaces la legislación y la jurisdicción. Resultaría, sin embargo, iluso por mi parte el intentar resolver problema de semejante trascendencia ahora y por quien esto escribe. De ahí que la cuestión se centre en asumir algún concepto de racionalidad que resulte mínimamente convincente y útil para el objetivo que perseguimos. A mi juicio, podría servir la idea de que con él se expresa la capacidad para mantener con un sector de la realidad social una interacción que se corresponde, que es coherente, con los datos que constituyen a tal realidad y que conocemos. Por lo demás, como con la legislación penal nos movemos en el campo del control social jurídico sancionador ${ }^{56}$, podríamos precisar más diciendo que, a nuestros efectos, es la capacidad para elaborar en el marco de ese control social una decisión legislativa atendiendo a los datos relevantes de la realidad social y jurídica sobre los que aquella incide. La definición, creo, no se aparta sustancialmente de otras que se han propuesto en este contexto por voces más autorizadas que la mía ${ }^{57}$, y no cierra

\footnotetext{
56 Ámbito que comparte el derecho penal, cuando menos, con el derecho administrativo sancionador.

${ }^{57}$ Atienza. 78-79, 85, habla, en terminología de Bobbio, de una razón fuerte, capaz de captar la esencia de las cosas, y estima que la precisamos para abordar problemas relativos a la
} 
el paso a propuestas de racionalidad discursiva que se ocupan de describir las condiciones que deben darse para que se obtenga un consenso respecto a lo que sea una decisión racional, esto es, coherente con la realidad social con la que se interactúa ${ }^{58}$. De un modo u otro, la racionalidad legislativa penal supondría el punto de llegada de una teoría de la argumentación jurídica, a desarrollar en el plano del proceder legislativo penal, que garantizara decisiones legislativas susceptibles de obtener amplios acuerdos sociales por su adecuación a la realidad social en la que se formulan ${ }^{59}$.

4.2. Los contenidos de racionalidad a los que deba atenerse el proceder legislativo, sin embargo, pueden ser de muy diverso alcance según la opción metodológica adoptada:

En amplios sectores jurídicos directamente implicados en la práctica de la elaboración de las leyes predomina lo que se ha denominado un modelo minimalista, especialmente preocupado por la obtención de la seguridad ju-

comprensión del mundo -conocimiento- y a cómo actuar en él -problemas prácticos-; Calsamiglia. 169, 174, que prefiere hablar de «cuestiones», antes que usar un concepto tan amplio y ambiguo como el de racionalidad, piensa que en todo caso se trata de lograr un instrumento para decidir con conocimiento de causa.

${ }^{58}$ En directa relación con la creación del derecho Habermas. 499-504 sostiene que la racionalidad de las decisiones se obtiene mediante la autonomía pública de los ciudadanos, que les hace igual de competentes a la hora de acordar las reglas que les rigen. Véase ampliamente sobre el concepto de racionalidad legislativa Atienza. 77-91.

Ya hemos visto que Luhmann rechaza toda racionalidad en la legislación, por estar carente de consistencia (supra apartado 2). Cabría añadir que, para él, los contenidos éticos y morales son ajenos al derecho -lo que permite precisamente el enjuiciamiento de éste desde el exterior-, y que la introducción en el sistema jurídico de aquellos intereses que han resultado más fuertes en el plano político no depende de su cualidad normativa sino de si encajan en las reglas de la autopoiesis del sistema. En cuanto al desarrollo de un procedimiento legislativo regulado jurídicamente, no hay que olvidar que tal procedimiento en ningún momento será capaz de influir en el sistema político, el cual lo utilizará a su conveniencia, pudiendo prescindir de él en cualquier momento. Por lo demás, estima que la pretensión de Habermas de que, sentados ciertos requisitos procedimentales, surgirá la razón, es ingenua pues pasa por alto que no se está en condiciones de meter en el discurso todos los aspectos relevantes. En realidad, pese a algunas manifestaciones en sentido contrario, Luhmann no cree que siquiera en la jurisdicción pueda hablarse de racionalidad, o, al menos, de algo más que una racionalidad local, centrada en la decisión concreta. Pues tampoco en la jurisdicción, por más que se busque la consistencia, se puede garantizar que la decisión sea la correcta. Y es que esa consistencia resultaría apresurado que la identificáramos sin más con la racionalidad jurídicoformal, a la que ciertamente se aproxima, pues sólo busca mantener el cierre operativo del sistema impulsada por el símbolo de la validez, que se limita a asegurar la constante reproducción intrasistémica de las operaciones, y por el criterio de la igualdad que, como fórmula de contingencia, evita que las decisiones del sistema estén siempre repitiéndose. Véase Luhmann. 98-117, 195-204, 214-238, 280-281, 321-323, 326-328, 400-402, 434-439, 557-561, 563-564.

${ }^{59}$ Apuntan claramente al desarrollo de una teoría de la argumentación jurídica legislativa, Atienza. 91 y ss.; Marcilla Córdoba. 101-107. Más escépticos, Salvador Coderch (1982). 80; Cano Bueso. 207-208. 
rídica. Tal modelo coloca el énfasis en el lenguaje legal, en la estructura de la ley y en su inserción sistemática dentro del conjunto del ordenamiento, es decir, lo que vamos a considerar más adelante las racionalidades lingüística y jurídico-formal ${ }^{60}$. Contenidos adicionales, referidos a los fines a perseguir por la ley y a los valores subyacentes, sin duda condicionan la tarea precedente, de la que son su presupuesto, pero deben quedar fuera porque son patrimonio de la actividad estrictamente política. A tales efectos es usual establecer una distinción entre técnica legislativa y ciencia de la legislación, que se correspondería con tal delimitación y que, aunque no parece que descargue a la segunda de la exigencia de racionalidad, la colocaría en cualquier caso en un plano distinto ${ }^{61}$.

En sentido opuesto, la concepción del derecho penal mínimo que desarrolla Ferrajoli acaba atribuyendo a la legislación una racionalidad casi exclusivamente ética, la cual, por otra parte, se formula sólo en términos negativos. En efecto, los contenidos externos de legitimación que el estado de derecho logra característicamente introducir dentro de su legitimación interna $^{62}$ están constituidos, por lo que se refiere al derecho penal, por criterios éticos sobre cuándo y cómo prohibir, penar o juzgar. Estos criterios garantistas son reflejo de unos derechos fundamentales que constituyen principios éticopolíticos externos al derecho y de él fundamentadores, que tienen su origen en la primacía a otorgar a la persona, y en la igualdad formal y material de ésta que ello exige. Por otro lado, tales garantías son formulables únicamente en sentido negativo, de forma que bajo los postulados de un derecho penal mínimo no se puede, por ejemplo, identificar un sistema de prohibiciones positivo legítimo ${ }^{63}$, y lo mismo podría decirse de las sanciones o del proceso, lo que justamente le diferencia frente a un rechazable derecho penal máximo que, al introducir criterios positivos, introduce la

${ }^{60}$ Véanse, con diferentes variantes, Salvador Coderch. (1982). 80; (1986). 11; (1989). 19, 28; Sainz Moreno. 20-22, quien incluye algún contenido adicional relativo al efectivo cumplimiento de la ley que podría considerarse inserto en una racionalidad pragmática; Tudela Aranda. 83-85, 86-89; Corona Ferrero. 50-52; Describen también, críticamente, esta actitud, Atienza.33-36; Marcilla Córdoba. 107-109.

61 Véanse Salvador Coderch. (1989). 15, 39, 42-43, 45; (1986). 23-25, por más que este autor considera que una ciencia de la legislación desarrollada permitiría avanzar a la técnica legislativa; Abajo Quintana. 123-125;

62 Véase lo dicho supra, apartado 3.

${ }^{63}$ Lo que le lleva en algunos pasajes a minusvalorar la actividad legislativa, frente a la jurisdiccional, en cuanto dedicada aquella a la satisfacción, mediante la regla de la mayoría, de intereses preconstituidos y directivas políticas más o menos contingentes. De ahí también que, cuando demanda una ciencia de la legislación, lo haga con el declarado propósito de asegurar la inclusión de esos principios éticos en las leyes, de forma que la jurisdicción pueda en su actuación respetar igualmente el principio de vinculación a la ley. 
discrecionalidad. Y es que el estado de derecho que da cobertura a tal derecho penal mínimo sirve más para deslegitimar que para legitimar decisiones de los poderes públicos ${ }^{64}$.

$\mathrm{Si}$ antes he sostenido que una decisión legislativa penal racional debe elaborarse atendiendo a los datos relevantes de la realidad social y jurídica con la que interactúa, no puedo compartir formulaciones reducidas de la racionalidad legislativa como las acabadas de recoger. Los partidarios de limitarse a una racionalidad técnicojurídica parecen buscar un campo de actuación alejado de las contingencias políticas, mucho más difíciles de afrontar racionalmente. Sin embargo, los contenidos éticos y estratégicos del debate político no se pueden eludir en fases más técnicas del proceder legislativo, en las que influyen de manera decisiva; pretensiones de neutralidad técnica ocultan una realidad operacional ${ }^{65}$ y conceptual $^{66}$ en la que se produce una constante aportación de contenidos procedentes de niveles de racionalidad más plurales que los señalados; su desconsideración o el intento de establecer una solución de continuidad entre unos niveles $u$ otros ${ }^{67}$ da una visión incompleta y por ello inexacta de lo que es un procedimiento legislativo racional. Por otra parte, como tendremos ocasión de ver, las mismas racionalidades lingüística y jurídicoformal precisan de un fundamento o apoyo ético, cuando menos, para poderse activar ${ }^{68}$. A su vez, la racionalidad legislativa que se desprende del derecho penal mínimo de Ferrajoli, aun cuando está dotada de unas sólidas bases éticas, resulta en extremo incompleta: Y ello no tanto porque se abstenga de proseguir el análisis de los ulteriores niveles de racionalidad de la legislación, pese a que ya dispone de los principios éticos de partida, cuanto porque el enfoque estrictamente garantista de los criterios identificados sólo permite averiguar aquello de lo que el legislador debe abstenerse, pero no aquello que debe hacer.

Afortunadamente existen otros enfoques teóricos que se corresponden mejor con el conjunto de exigencias de racionalidad que el legislador debe atender: En el campo de la sociología jurídica hay que destacar sin duda la postura de Habermas, quien ha manifestado contundentemente que todo

\footnotetext{
64 Véase Ferrajoli. 347-362, 460-465, 553-556, 591-594, 908-909, 913-914, 947-963.

65 Véase al respecto Díez Ripollés. (2002). passim.

66 Véase lo dicho infra sobre la interrelación entre las diversas racionalidades.

${ }^{67}$ No creo que merezca la pena entrar aquí en un análisis de lo que debería denominarse técnica legislativa, o ciencia, o teoría, de la legislación. Intento en estas páginas describir los contenidos de la racionalidad legislativa en su totalidad, y la adscripción de los contenidos a un lugar u otro es ahora secundario y quizás perturbador. Por lo demás hay también otras formas de diferenciar entre ambos conceptos que no presuponen una partición de las racionalidades en dos bloques disciplinares distintos. Véanse Atienza. 17-23; Marcilla Córdoba. 107-109.

${ }^{68}$ Véase también una crítica a este enfoque en Atienza.33-36.
} 
procedimiento legislativo democrático ${ }^{69}$ debe atender a contenidos morales y éticos, a intereses, a cuestiones pragmáticas y a fórmulas de coherencia jurídica ${ }^{70}$. En la filosofía del derecho ha tenido especial eco entre nosotros la propuesta amplia formulada por Atienza, quien identifica una racionalidad legislativa estructurada en cinco niveles, los cuatro primeros instrumentales y uno último justificador. Tendríamos así los niveles o, mejor, racionalidades siguientes: Lingüística, jurídicoformal, pragmática, teleológica y ética. Estas cinco racionalidades estarían a su vez afectadas por una dimensión transversal, la eficiencia, que afectaría a cada una de ellas dentro de sus límites. Pues bien, tales racionalidades podrían ser objeto de un análisis individualizado ${ }^{71}$, así como de otro que se ocupara de destacar las interrelaciones entre ellas, tras lo cual se podrían realizar afirmaciones generales sobre la racionalidad de la concreta decisión legislativa ${ }^{72}$. Dentro del derecho penal, Amelung ha propuesto vincular la política criminal a los modelos racionales de planificación desarrollados por la ciencia política, que contemplan muy diversos criterios de racionalidad, tanto de naturaleza material como instrumental, y Palazzo ha defendido la involucración de la doctrina jurídicopenal en el desarrollo de un método de creación de leyes que garantice tanto una racionalidad lingüística o jurídicoformal, como una racionalidad de fines, orientada en las corrientes políticocriminales subyacentes, y una racionalidad instrumental que procure asegurar las condiciones empíricas para su obtención ${ }^{73}$.

4.3. A mi juicio, la propuesta de Atienza identifica y reparte de manera convincente los diferentes contenidos de racionalidad a tener en cuenta en la legislación, y es la que voy a tomar como punto de referencia a partir de este momento. Sin embargo, estimo conveniente precisar algunos aspectos y marcar algunas diferencias respecto al citado modelo, precisiones y diferencias que probablemente estarán en alguna medida condicionados por el enfoque jurídicopenal que está en el trasfondo.

${ }^{69} \mathrm{Al}$ igual que todo modelo procedimental de formación de la voluntad política y, en sentido más abstracto, toda explicitación del principio del discurso en relación con normas jurídicas.

70 Véase Habermas. 187-201, 203-207, 217-225, 285-291, 340-348. Capta acertadamente la utilidad de la teoría del discurso de Habermas para la elaboración de la racionalidad legislativa, Soto Navarro. 76-77.

${ }^{71}$ En el proceso de producción legislativa interactuarían siempre cinco elementos, cuya diversa configuración en cada racionalidad marcaría una vía de profundización en el análisis del nivel respectivo. Tales elementos serían: Edictor -autor de la norma-, destinatario -aquél a quien va dirigida-, sistema jurídico -conjunto del que pasa a formar parte la ley-, fin -objetivo perseguido-, y valor -justificación del fin-.

72 Véase Atienza. 24-63, 77-91. Han asumido la propuesta de Atienza, entre otros, Calsamiglia. 169-175, 178; Marcilla Cordoba. 108-115; Aguiló Regla. 249-251.

73 Véanse Amelung. 22-31; Palazzo. 734-735. 
En primer lugar, creo que el estudio de las diversas racionalidades debe realizarse de modo inverso a como procede Atienza: Si lo que queremos es establecer un procedimiento racional de elaboración de leyes, y no simplemente un instrumental de análisis racional de leyes ya existentes ${ }^{74}$, la racionalidad ética marcaría el ámbito de juego de las restantes racionalidades, la teleológica establecería los objetivos a satisfacer dentro de ese marco, y las restantes se sucederían en un orden de proyección decreciente de instrumentalidad.

En segundo lugar, considero que a través de la racionalidad ética se saca a la luz el sistema de creencias, cultural e históricamente condicionado, que sustenta a una determinada colectividad ${ }^{75}$, y en el que se ha de enmarcar necesariamente el proceder legislativo. En terminología de Habermas, se trata de identificar el mundo de la vida de los integrantes de la colectividad, aquel conjunto de actitudes vitales y principios reguladores del comportamiento que, en cuanto compartidos de forma generalizada, no están normalmente sometidos al principio del discurso sino que modulan todo actuar comunicativo. Es cierto que cambios culturales, repentinos o paulatinos pero por lo general ocurrentes en amplios intervalos temporales, pueden hacer necesario el sometimiento de tales contenidos éticos a un discurso racional, pero en todo caso darán lugar a un perfil bajo de debate, en el marco de grandes consensos y sin intereses particulares de por medio. Cada sector del ordenamiento jurídico dispone de sus criterios o principios éticos específicos, referidos al conjunto de interacciones con la realidad social propio de ese sector, por más que se producirán un buen número de coincidencias intersectoriales, y que todos ellos serán coherentes con los criterios éticos que inspiran al ordenamiento en su totalidad ${ }^{76}$.

Dentro de los contenidos éticos que condicionarían la intervención jurídicopenal habría que distinguir en primer lugar unos principios que podríamos denominar estructurales de primer nivel, divididos a su vez en tres grandes grupos, y que establecerían los contornos básicos de una interven-

${ }^{74}$ Así lo pone de manifiesto con razón el propio Atienza. 91-92. Todo ello sin perjuicio del cambio de enfoque que viene impuesto en la fase postlegislativa, a la hora de evaluar leyes ya existentes. Véase sobre esta fase Díez Ripollés. (2002). 29 y ss. Texto Word.

${ }^{75}$ Utilizo un concepto de ética diferenciado del de moral, en un sentido similar al que ha asumido Habermas. 187-207, 217-225, 285-287, en virtud del cual los contenidos morales poseen una validez universal, para cualquiera, mientras los éticos son válidos dentro de una determinada colectividad a partir de la autocomprensión que comparten sus integrantes. De todos modos, veáse la matización que hago un poco más abajo.

${ }^{76} \mathrm{Su}$ identificación podría verse como un primer paso en la tarea señalada por Habermas de descomponer el original sistema de derechos, obtenido mediante el principio discursivo y el medio jurídico, y habitualmente reflejado en las Constituciones, en un conjunto de principios y derechos más detallado en el marco del estado de derecho. Véase Habermas. 158-160. 
ción penal legítima: Los principios de la protección atenderían a las pautas delimitadoras de los contenidos de tutela del derecho penal. Los principios de la responsabilidad se ocuparían de los requisitos que deben concurrir en un comportamiento para que se pueda exigir responsabilidad criminal por él, y de algunos aspectos de su verificación. Y los principios de la sanción destacarían los fundamentos de la reacción con sanciones a la conducta criminalmente responsable ${ }^{77}$. A estos principios les es común su origen ético, es decir, una legitimación vinculada a las profundas convicciones culturales de la colectividad ${ }^{78}$, por más que el desarrollo de sus componentes en las subsiguientes racionalidades les pueda llevar a operar, según los casos, en planos éticopolíticos, pragmáticos, de consistencia o de comunicabilidad.

A la racionalidad ética pertenece igualmente el criterio democrático, esto es, el criterio que, una vez aseguradas con los principios estructurales las referencias éticas, va a permitir legitimar decisiones concretas controvertidas en las subsiguientes racionalidades, o en la interrelación entre ellas. Este criterio, en el que nos detendremos más adelante, remite a las convicciones sociales ampliamente mayoritarias, y tiene una relevancia distinta según la racionalidad de la que se trate: De gran importancia en la racionalidad teleológica, desciende en significación a medida que se avanza en los niveles de racionalidad, recuperando de nuevo su importancia cuando se trata de acomodar al conjunto de ellas ${ }^{79}$.

Por lo demás, la propia estructura en cinco niveles de la racionalidad legislativa es una cuestión ética. Se podrá discutir en qué medida los juristas deben ocuparse del conjunto de los niveles de la racionalidad legislativa o, más bien, deben dejar a los políticos la determinación de algunos de ellos, pero en todo caso, salvo mejores argumentos, no parece que nuestra interacción con la realidad social que ha de ser sometida eventualmente al control social jurídico sancionador deba atender a muchos más contenidos de racionalidad.

Queda, sin duda, la cuestión de los contenidos morales, y no meramente éticos ${ }^{80}$ : Con todo, si aceptamos el planteamiento discursivo de Habermas, creo sostenible afirmar que su diferencia descansa realmente en el diferente grado de aceptación que logran, universal en los primeros, cultural

${ }^{77}$ Véase una referencia a estos principios, y una provisional profundización en los de tutela y de sanción, en Díez Ripollés. (1997). 12-13; (2000). 6-14.

${ }^{78}$ Los principios garantistas, puramente negativos, de Ferrajoli -vid. Supra-, responderían a una caracterización de la racionalidad ética sustancialmente coincidente. Véase Ferrajoli. 460465, 947-950, 956-959.

${ }^{79}$ De hecho es un criterio que puede llegar a desempeñar excepcionalmente un papel dentro de la propia racionalidad ética, en tiempos de profundas variaciones culturales, pero en un contexto limitado. Véase supra.

${ }^{80}$ Véase la distinción apuntada supra. 
e históricamente condicionada en los segundos, pero la aceptación tanto de unos como de otros se ha de obtener, a nuestros efectos, en el mismo lugar, el discurso creador de normas jurídicas, y bajo las mismas condiciones, un determinado contexto ético o mundo de la vida ${ }^{81}$. En consecuencia, bien puede decirse que a efectos operativos los criterios morales se incluyen en la racionalidad ética, con la peculiaridad de que poseen un poder de convicción discursiva mayor.

En tercer lugar, y por lo que se refiere a la racionalidad teleológica, no comparto el punto de vista de Atienza de que se ha de ocupar de la eficacia de la ley, esto es, de si se pueden lograr los objetivos sociales perseguidos por ella ${ }^{82}$. Sin duda éste es un importante aspecto que deberá ser sometido a consideración en alguna racionalidad, pero creo que hacerlo ya en este momento supone obviar el debate sobre los objetivos legales mismos. Así como en la racionalidad ética hemos descubierto los principios incuestionados que deben orientar cualquier decisión legislativa penal, se trata ahora, en esta racionalidad, de sentar las bases para un discurso ético-político en el que, presupuestos los principios anteriores, se produzca una confrontación racional entre contenidos éticos de segundo orden, es decir, carentes de una aceptación libre de cualquier desacuerdo en la colectividad, e intereses particulares y sectoriales muy diversos, procedentes todos ellos de agentes sociales y grupos de presión de amplio espectro ${ }^{83}$. Tal confrontación implicará la obtención de compromisos, y un empleo decisivo del criterio democrático. De ella habrán de surgir, en el ámbito jurídicopenal en el que nos movemos, una formulación de los objetivos perseguidos por esa concreta decisión legislativa penal, que determine, cuando menos, el objeto de tutela, su grado de protección deseable, y los correspondientes niveles de exigencia de responsabilidad y de sanción aplicable que se estiman procedentes en caso de incumplimiento de la norma. De este modo se reflejará el acuerdo éticopolítico alcanzado sobre la importancia de lo protegido, la intensidad de la obediencia exigida, las repercusiones negativas derivadas de tal desobediencia, y su interrelación.

\footnotetext{
81 Véase algunas insinuaciones en ese sentido en Habermas. 161-163, 390-395.

82 Véase Atienza. 28, 38, 46-49, quien, con todo, incluye en ocasiones en esta racionalidad la identificación de los objetivos a obtener (38). Concibe esta racionalidad como orientada a la eficiencia de la ley, esto es, al aseguramiento de una correspondencia entre los recursos escasos y los fines pretendidos, Calsamiglia. 172-173, 175-176.

83 Véase en Habermas. 187-195, 203-207, 340-348, un reconocimiento del momento de contraposición entre contenidos éticos y morales, e intereses, en la formación deliberativa y democrática de la voluntad política.

Sobre el modo en que se desenvuelven los agentes sociales y los grupos de presión en el proceso legislativo penal, véase Diez Ripollés. (2002). Passim.
} 
Creo, en cuarto lugar, que es la racionalidad pragmática la que tiene la misión de ajustar los objetivos trazados por la racionalidad teleológica a las posibilidades reales de intervención social que están al alcance de la correspondiente decisión legislativa. Ello implica, en el ámbito jurídicopenal, asegurar lo más posible una respuesta positiva a una serie de exigencias mutuamente entrelazadas planteadas a la norma: Que el mandato o la prohibición sean susceptibles de ser cumplidos, satisfaciendo así la función de la norma como directiva de conducta. Que se va a estar en condiciones de reaccionar al incumplimiento del mandato o la prohibición mediante la aplicación coactiva de la ley, satisfaciendo así su función como expectativa normativa; la pregunta se extiende desde la persecución policial hasta la ejecución de la sanción, pasando por la activación de la administración de justicia $^{84}$. Que el directo cumplimiento de la norma es presumible que produzca los efectos de tutela perseguidos. Que la aplicación contrafáctica de la norma va a producir indirectamente esos mismos efectos de tutela. Y que la aplicación de la norma se va a poder mantener dentro de la delimitación perseguida de la responsabilidad y de la sanción. Mientras las dos primeras exigencias se ocupan de la efectividad de la norma, esto es, de su puesta en práctica o vigencia, las tres restantes lo hacen de su eficacia, es decir, de la obtención de los objetivos de tutela perseguidos ${ }^{85}$. Ambos aspectos, en cualquier caso, forman parte de una racionalidad pragmática que, en el ámbito del control social jurídico sancionador, tiene como presupuesto necesario, aunque no suficiente, para la obtención de los efectos de tutela pretendidos, la incidencia de la norma sobre los ciudadanos destinatarios de ella ${ }^{86}$.

Comparto por lo demás la habitual caracterización de las racionalidades jurídico-formal y lingüística, la primera encaminada a asegurar un sistema jurídico coherente, y la segunda a garantizar las habilidades comunicacio-

\footnotetext{
${ }^{84}$ Apunta a esta distinción entre cumplimiento y aplicación Calsamiglia. 171-172. Véase también la ilustrativa referencia que hace Larrauri Pijoan. (2001). 98 al escaso uso de esa diferencia terminológica en nuestro lenguaje políticocriminal frente al hábito contrario anglosajón.

${ }^{85}$ Véase una clara distinción entre ambos aspectos en derecho penal, en Hassemer-Steinert-Treiber. 20.

${ }^{86}$ La propuesta realizada supone introducir la mayor parte de la racionalidad teleológica de Atienza en la racionalidad pragmática. Con todo hay que destacar que él mismo es consciente de la difícil diferenciación entre ambas, y que, al analizar las racionalidades en sentido inverso a como nosotros lo hacemos, considera aspectos de efectividad previamente a los de eficacia. Véase Atienza. 27-28, 36-38, 42-49. Parece vincular en la racionalidad pragmática la eficacia y la efectividad, Calsamiglia. 167-168, 171-172, quien, por lo demás, nos recuerda la dificultad ínsita en la previsión de consecuencias.

Por otro lado, la medida en que la distinción entre racionalidad teleológica y pragmática se superpone con la ahora en Alemania profusamente utilizada distinción entre "Verhaltensnorm" und "Sanktionsnorm" es algo que dejamos para otro momento. Véase recientemente Haffke. 955 y ss.
} 
nales de las normas ${ }^{87}$. Considero asimismo un acierto la configuración por Atienza de la eficiencia como una dimensión transversal, que no constituye un nivel de racionalidad independiente sino una cualidad exigible a cada una de las racionalidades y a la interrelación entre ellas. Dentro de cada racionalidad, asumiendo la pluralidad de contenidos existente, se trataría de prevenir que la priorización de ciertos aspectos en detrimento de otros no llegara hasta el punto de que ya no correspondiera a un análisis de coste-beneficio. Y un papel semejante jugaría en el momento de integrar las diversas racionalidades en una sola norma legal ${ }^{88}$.

A partir de los presupuestos anteriores, una ley padecerá de irracionalidad ética si no se ajusta en su contenido a los criterios o principios éticos incuestionados del sector jurídico en el que nos movamos, en el caso del derecho penal, los principios estructurales antedichos. También carecerá de ella si renuncia al criterio democrático como principio último de resolución de las controversias dentro y entre las subsiguientes racionalidades ${ }^{89}$, o si prescinde de una estructura de racionalidad legislativa equivalente a la vigente en un determinado momento histórico y cultural. La irracionalidad teleológica aparecerá en la medida en que los objetivos a perseguir por la ley no hayan sido acordados en el marco de un empleo discursivo del criterio democrático, que haya prestado la debida atención a todos los componentes éticopolíticos relevantes, o no reflejen tal acuerdo. La irracionalidad pragmática surgirá, tanto ante leyes penales que no son susceptibles de un apreciable cumplimiento por los ciudadanos o de una significativa aplicación por los órganos del control social jurídico sancionador, cuanto ante leyes que, en cualquier caso, no logran los objetivos pretendidos. La irracionalidad jurídicoformal la poseerán leyes inconsistentes consigo mismas o que introducen o dejan sin resolver incoherencias en el sector jurídico en el que se insertan o en el conjunto del ordenamiento. Y la irracionalidad lingüística afectará a leyes cuya formulación impide o dificulta la transmisión de sus contenidos a los destinatarios de su cumplimiento o aplicación ${ }^{90}$.

Por último, y como Atienza ha señalado ${ }^{11}$, la racionalidad legislativa precisa para su plenitud considerar la interrelación entre sus diversos ni-

${ }^{87}$ Véase Atienza. 27-36. Con razón previene Calsamiglia. 170, 176-177 frente a la tentación de trasponer sin más los criterios habituales de consistencia y sistematicidad propios de la aplicación del derecho a su creación, abogando por una elaboración relativamente autónoma de estos últimos.

88 Véase Atienza. 93-94.

${ }^{89}$ El real pero limitado papel que juega en la racionalidad ética ya lo hemos señalado.

90 Sobre los diferentes supuestos de irracionalidad no podemos detenernos ahora. Un estudio pormenorizado de cada una de las racionalidades sería el lugar de análisis adecuado. Véase con todo los cuidadosamente identificados por Atienza. 29-30, 33, 37, 38, 39, 44-48.

91 Véase Atienza. 57-63, respecto a lo que él llama, con poco acierto, estática legislativa. 
veles $^{92}$. A este respecto, una regla operativa útil en caso de conflicto puede ser la de que los niveles superiores primen sobre los inferiores, es decir, el ético sobre todos, el teleológico sobre el pragmático, jurídicoformal y lingüístico, etc. Sin embargo, este criterio debe matizarse, pues la idea de eficiencia aconseja que se aspire en todo momento a lograr un equilibrio óptimo entre las diversas racionalidades, de modo que en ningún caso el aseguramiento de un determinado nivel de racionalidad conlleve la anulación de otro u otros ${ }^{93}$. Esta pretensión, por otra parte, será en ocasiones lo suficientemente compleja de llevar a cabo como para que haya que acudir ${ }^{94}$ al criterio democrático para dilucidar las pérdidas de racionalidad socialmente asumibles.

Bajo esos parámetros, y sólo a título ejemplificativo ${ }^{95}$, es fácil imaginar que la racionalidad ética tropezará con la teleológica cuando ésta se trace objetivos incompatibles con los criterios éticos fundamentales, con la pragmática cuando ésta busque asegurar la aplicación de la ley aun a costa de ciertas garantías ciudadanas, o con la jurídicoformal y lingüística cuando se vea conveniente mermar la seguridad jurídica o precisión comunicacional para favorecer ciertos márgenes de equidad en el caso concreto. Y que la teleológica, además, se verá frecuentemente confrontada con la pragmática a la hora de garantizar la obtención de sus objetivos, o con la jurídicoformal si pretende establecerlos sin preocuparse de su encaje en el conjunto de pretensiones vigentes en el actual ordenamiento jurídico.

4.4. En otro lugar he expuesto la necesidad de que todo modelo de legislación racional evite quedarse en el plano puramente prescriptivo, en el que se identifican los diversos contenidos de racionalidad a tener en cuenta, pero al que no le es directamente accesible el contexto operacional en el que tales racionalidades han de desenvolverse. A tales efectos he desarrollado un modelo dinámico de legislación penal, que describe y analiza críticamente el concreto funcionamiento del proceder legislativo, creando así las bases para el efectivo asentamiento de las diversas racionalidades en la práctica legislativa ${ }^{96}$. Concluida una primera formulación de la estructura y

\footnotetext{
92 Me refiero en este pasaje a casos de conflicto entre racionalidades. Otra forma de interrelación entre ellas es la que se da en la medida en que las exigencias de una coadyuvan a la obtención de otra u otras. Véanse sobre estos casos, no problemáticos mientras se mantenga claramente la delimitación entre los elementos correspondientes a cada racionalidad, Atienza. 57-63; Calsamiglia. 172-178; Sainz Moreno. 20-22.

93 En este sentido Atienza. 92-94.

${ }^{94}$ Por lo general sólo de la racionalidad teleológica para abajo. Véase supra el limitado papel del criterio democrático en la racionalidad ética.

95 Véase más ampliamente Atienza. 58-63. También Calsamiglia. 169, 170-171, 174.

96 Véase Díez Ripollés. (2002). Passim.
} 
contenidos de la racionalidad legislativa, puede resultar útil realizar una provisional distribución de sus niveles dentro de las diferentes fases y etapas de la dinámica legislativa, no sin destacar desde el primer momento el diferente grado en que cada una de las racionalidades habrá de estar presente en los respectivos tramos operacionales ${ }^{97}$.

Las racionalidades que predominarán en la fase prelegislativa varían sustancialmente según la etapa de ella en la que nos encontremos. Durante las primeras etapas, de acreditación de una disfunción social, consolidación del correspondiente malestar colectivo y configuración de una opinión pública, es la racionalidad teleológica condicionada por la ética la que ocupa el primer plano; sin embargo, la racionalidad pragmática se va progresivamente esbozando, en especial cuando en la opinión pública se aprecian formulaciones cercanas a un programa de acción. La racionalidad pragmática es la que ocupará el primer plano en la elaboración de programas de acción por los grupos de presión expertos, quienes se introducirán además con alguna frecuencia en el contexto de la racionalidad jurídicoformal y lingüística; por el contrario, los programas de acción de los grupos de presión mediáticos y populistas será extraño que alcancen la racionalidad pragmática, y sólo limitada o excepcionalmente se ocuparán de la racionalidad jurídicoformal o lingüística. En la elaboración de los proyectos o proposiciones de ley por las burocracias estará presente el conjunto de racionalidades, si bien será frecuente que la racionalidad teleológica venga ya muy condicionada y el trabajo se centre en las racionalidades pragmática, jurídicoformal y lingüística, con la debida toma en consideración de la ética ${ }^{98}$.

En las diferentes etapas de la fase legislativa estarán presentes en todo momento las cinco racionalidades. La evolución apreciada en la fase prelegislativa desde una racionalidad ética a una lingüística no se registrará en esta fase. Al contrario, volverán a replantearse cuestiones de racionalidad ética y teleológica, que con frecuencia pasarán a ocupar más espacio en el debate que, desde luego, las racionalidades jurídicoformal y lingüística. Es el periodo del proceder legislativo en el que, por otra parte, saltarán a primer plano las posibles incompatibilidades entre las diversas racionalidades ${ }^{99}$.

En la fase postlegislativa se atiende de manera muy segmentada a las diversas racionalidades, consecuencia de que las plurales actividades de eva-

\footnotetext{
${ }^{97}$ En lo que sigue me remito a los conceptos desarrollados en Díez Ripollés. Ibídem.

${ }^{98}$ Para Atienza. 69 en esta fase están especialmente implicadas las racionalidades teleológica -que incluye contenidos por mí considerados pragmáticos- y ética; para Rodríguez Mondragón. 85-87 parecen predominar en esta fase las racionalidades ética, teleológica y pragmática.

${ }^{99}$ Para Atienza. 69 están implicadas todas las racionalidades; para Rodríguez Mondragón. 87-88 parece que predominan las racionalidades jurídicoformal y lingüística, aunque también están presentes la teleológica y la pragmática.
} 
luación desarrolladas se suelen focalizar cada una de ellas en una u otra de esas racionalidades. En cualquier caso, predominará la racionalidad pragmática, y luego la jurídicoformal ${ }^{100}$.

A salvo la necesaria profundización en la imbricación entre los contenidos de racionalidad y las fases operacionales del proceder legislativo ${ }^{101}$, lo hasta ahora visto permite sacar ya alguna conclusión relevante. Singularmente la de que la racionalidad legislativa no es, ni mucho menos, un asunto de juristas, técnicos o legisladores, sino que se desenvuelve en ámbitos sociales muy diversos. De especial significación resulta detenerse en la fase prelegislativa y observar en qué importante medida en las etapas previas a la de intervención de las burocracias entran en acción casi todas las racionalidades.

\section{El desarrollo de la racionalidad legislativa penal}

Establecidos los contenidos básicos de una racionalidad legislativa que podría acomodarse a las necesidades jurídicopenales, el siguiente paso habría de consistir en dotar a los diversos niveles de racionalidad de principios, reglas y criterios diferenciados. Sólo ese desarrollo ulterior de la teoría de la legislación, que debiera especificarse según los sectores jurídicos objeto de atención, va a permitir enriquecer sus contenidos de modo que pueda abandonar meras caracterizaciones globales sobre cómo debiera ser el proceder legislativo y estar en condiciones de aportar instrumentos útiles para la elaboración del derecho. Los avances ya registrados genéricamente sobre las racionalidades lingüística y jurídico formal ${ }^{102}$ deben especificarse en función de los diversos sectores jurídicos a los que atienden, y deben extenderse al resto de racionalidades. Sin duda la identificación de las disciplinas científicas o técnicas que tienen más importancia en cada una de las racionalidades es una labor meritoria ${ }^{103}$, pero un progreso sustancial sólo será posible si se avanza en las tareas acabadas de reseñar.

5.1. Pero antes de realizar progresos en la identificación y concreción de esas pautas en los diversos niveles de la racionalidad legislativa penal, hay que responder convincentemente a una pregunta: Si tiene sentido construir en derecho penal una nueva estructura conceptual, a cuenta de la creación

\footnotetext{
${ }^{100}$ Para Rodríguez Mondragón. 89 también predominará la racionalidad pragmática; para Atienza. 69 están en primer plano la jurídicoformal, pragmática y teleológica.

${ }^{101}$ Que, como tantos otros aspectos de una teoría de la legislación, se mueve todavía en un plano preliminar.

102 Plasmados en las Directrices legislativas vigentes en diversos países. Véase en España, de modo especial, Acuerdo del Consejo de ministros de 18-10-91. 40.

${ }^{103}$ Véase por ejemplo la tarea a este respecto realizada por Atienza. 30-31, 33, 37, 38, 39-
} 
de las leyes penales, pasando por alto que disponemos ya de teorías como la del bien jurídico, la jurídica del delito y la de los fines de la pena, cuya solidez, en especial la de las dos últimas, parece ofrecer expectativas de poder atender directamente a los problemas que nos preocupan ${ }^{104}$. En resumidas cuentas, ellas ya habrían llevado a término la tarea de plasmar el conjunto de racionalidades en el derecho penal.

Considero que, al margen de los argumentos generales, hay dos buenas razones para desarrollar una teoría de la legislación penal que, sin abdicar de los logros ya obtenidos en otros ámbitos de la reflexión jurídicopenal, ofrezca nuevas perspectivas de profundización en contenidos de racionalidad.

- La primera de ellas tiene que ver con la necesidad de liberar a la reflexión jurídicopenal de las ataduras impuestas por las consecuencias del positivismo jurídico, y que le han impedido desarrollar todas sus potencialidades racionalizadoras: Aunque en menor medida que en otros sectores jurídicos, hemos podido comprobar cómo el desplazamiento del énfasis desde la legislación a la aplicación del derecho ha afectado también de lleno al derecho penal ${ }^{105}$. Aun a riesgo de repetir algo de lo ya dicho ${ }^{106}$, conviene recordar que la consolidación del positivismo jurídico sentó las bases de una determinada manera de acercarse científicamente al derecho penal: Hay que partir del derecho puesto, del derecho ya dado, mientras que la creación del derecho se deja en manos de un legislador al que en buena medida no se le plantean exigencias de racionalidad, exigencias que se reconducen a la aplicación del derecho ${ }^{107}$. La doctrina penal reacciona a esta situación de manera defensiva, no cuestionando la premisa mayor, la irracionalidad del legislador, sino intentando contrarrestarla mediante la racionalidad del aplicador del derecho, lo que implica dedicarse a racionalizar el derecho ya existente, considerado incuestionable.

Eso explica que la legitimación del derecho penal se construya por la doctrina penal desde la teoría de los fines de la pena: Lo que hay que legitimar no son los contenidos de tutela o las estructuras básicas de exigencia de responsabilidad, ni siquiera el sistema de penas. La determinación de todo eso compete a un legislador político cuyas decisiones son incuestiona-

${ }^{104}$ En último término, no se puede negar que ellas se han edificado en buena medida, correctamente, a partir de los contenidos de la racionalidad ética.

105 Véase supra apartado 1.

106 Véase el párrafo del apartado 1 relativo al confinamiento de los penalistas en la aplicación del derecho.

${ }^{107} \mathrm{El}$ estado de derecho constitucional crea ciertamente una racionalidad legislativa en su plano más elevado, la constitución, pero, como hemos visto, ella repercute escasamente sobre el legislador, ejerciendo sus efectos especialmente en la aplicación del derecho, con el fenómeno de la judicialización. 
bles. Lo que hay que justificar desde perspectivas éticas y teleológicas es simplemente la naturaleza de los efectos a lograr con una sanción así predeterminada. Por otro lado, esa trascendente reducción de los contenidos a legitimar ${ }^{108}$ se ve potenciada en el debate contemporáneo por diversos factores: Uno de ellos es la reconducción de los planteamientos retributivos, abandonados los enfoques del idealismo alemán, a determinadas modalidades de prevención general ${ }^{109}$; otro, el afianzamiento de las teorías unitarias de la pena, que han sido capaces de desactivar los aspectos más problemáticos de las diversas teorías preventivas. Como consecuencia de ello, el debate actual sobre la pena ha abandonado en gran medida incluso el plano ético o teleológico para girar especialmente sobre problemas de racionalidad pragmática y, aun dentro de ella, más sobre problemas de efectividad que de eficacia: Se trata primordialmente de verificar qué efectos son los más adecuados para asegurar que cualesquiera leyes realmente se cumplan $\mathrm{o}$, en su defecto, se apliquen ${ }^{110}$. Mientras, por encima de toda esta evolución epistemológica sobrevuela el problema de la fundamentación de la pena -y sólo en cuanto de la pena, se dice, también del derecho penal-, aspecto al que se reconoce su primacía sobre la teoría de los fines de la pena pero al que se remite vagamente a la teoría sobre los objetos de tutela ${ }^{111}$.

Un poco más tarde la reflexión jurídicopenal se dedica asimismo a construir un sistema de responsabilidad que en todo momento se reclama destilación refinada del derecho vigente, al que interpreta y sistematiza. De ahí que asuma con entusiasmo la denominación de dogmática, como sinónimo de cientificismo, en cuanto se liga a un hecho, el derecho positivo, como dogma. Es cierto que la extremada perfección adquirida por tal sistema y plasmada en la teoría jurídica del delito ha hecho que terminara influyendo notablemente en la creación del derecho a la hora de fijar los criterios de responsabilidad; pero lo ha hecho mediante la detección de quiebras en el derecho vigente. Y lo que es más importante, incluso en tales casos se ha

108 Por más que a partir de las conclusiones obtenidas sobre la legitimación de los efectos de la pena, pero sólo a partir de ellas, se puedan derivar consecuencias respecto a la naturaleza de los objetos de tutela, contenidos de la responsabilidad y configuración de las penas.

${ }^{109}$ Véanse, por todos, respecto a la aproximación de las modernas teorías retributivas a las preventivogenerales integradoras, Hassemer-Steinert-Treiber.162; Silva Sánchez. (1992). 198-210.

110 Véase sobre todos estos conceptos supra apartado 4.3.

Por otra parte, de ese descenso del debate doctrinal a niveles de racionalidad inferiores no se libran, desde luego, ni las perspectivas abolicionistas, que se limitan a replantear el problema prestando especial atención a los ámbitos extrapenales

111 Véase una crítica a la fundamentación del derecho penal exclusivamente desde la teoría de los fines de la pena en Díez Ripollés. (1988). 1086-1087; (1991). 789 y ss.; (2001). 6; Silva Sánchez. (1992). 179-181, 187-188, 193, 195-196, 217, 281; Valle Muñiz. 22; Prieto del Pino. 361-367. 
visto a sí misma desde una perspectiva negativa, condicionada por la iniciativa de otros, del legislador, lo que explica la presentación de sus principios básicos como principios limitadores ${ }^{112}$, o su habitual denominación como derecho penal garantista.

Y es al final de esta evolución cuando la reflexión penal se ha ocupado de construir una teoría sobre los contenidos de protección, a partir de la teoría del bien jurídico. Teoría, sin embargo, que no se aparta del enfoque garantista, meramente limitador de las iniciativas del legislador, ya adoptado por el sistema de responsabilidad. En este sentido, se adopta la sorprendente tesis de que, como las sanciones del derecho penal son muy graves, se han de restringir los objetos de tutela, lo que explicaría el principio de fragmentariedad, de subsidiariedad... . Lo lógico, por el contrario, hubiera sido seleccionar primero los objetos de tutela especialmente importantes, y plantearse luego desde criterios éticos, teleológicos y pragmáticos hasta donde se puede llegar para su protección en el uso del arsenal sancionador disponible en el estado de derecho constitucional.

En suma, la reflexión jurídicopenal se ha visto atrapada en una estrategia equivocada: No hay que asumir el arbitrio irracional del legislador e intentar atemperarlo mediante principios limitadores en el momento de la aplicación del derecho ${ }^{113}$, sino que hay que someter al legislador desde el inicio de su actividad a criterios racionales de legislación, previendo los medios jurídicopolíticos para ello.

Un ejemplo significativo de lo difícil que resulta eludir la trampa puesta desde hace décadas por el positivismo jurídico a la reflexión jurídicopenal es, entre nosotros, la postura metodológica adoptada por Silva Sánchez: Aunque el autor en algún momento parece considerar que es a través de las reformas legales, de la legislación, como se puede lograr de manera determinante que los fines y valores legitimadores que aporta la política criminal encuentren su debido reflejo en el derecho penal, en un momento temprano de su exposición, al adoptar la trascendente decisión de que es la dogmática el lugar fundamental de reflexión jurídicopenal, desplaza definitivamente el centro de atención de la creación a la aplicación del derecho. Ciertamente tal quiebro argumental no conlleva una restricción del razonamiento jurídicopenal, desde ahora dogmático, a la mera interpretación y sistematización del derecho positivo; muy al contrario, defiende una dogmática que se afana en la búsqueda de las premisas valorativas del derecho penal ${ }^{114}$, lo

\footnotetext{
112 Véase cita precedente.

113 O durante su creación pero formulándolos desde una localización periférica.

${ }^{114}$ La medida en que la atribución de tal tarea a la Dogmática supone una suplantación por ésta de la misión propia de la Política criminal, que el propio Silva ha dicho previamente (véase, entre otros lugares, Silva Sánchez. (1992). 43-48) que es la encargada de identificar los
} 
que le conduce a los valores socioculturales vigentes, en cuya identificación será punto de referencia necesario, aunque no suficiente, la Constitución, pues el carácter abierto e impreciso de ésta obliga a acudir a los contenidos de una filosofía jurídica que sea compatible con los valores constitucionales y refleje los valores culturales dominantes. Pero lo que aquí nos interesa destacar es que todo ese proceso reflexivo, en la medida en que se realiza en el plano dogmático, tiene un límite irrebasable, que Silva se encarga de recordar en muy diversos lugares, el derecho positivo: La determinación de los fines del derecho penal, la construcción del sistema de atribución de responsabilidad penal... tienen amplios márgenes para la argumentación de diferentes alternativas, pero todas ellas han de ser compatibles con los enunciados del derecho positivo ${ }^{115}$.

Es indudable, como se encarga de recordar Silva, que la reflexión dogmática puede llegar a conclusiones críticas sobre el derecho vigente, pero la perspectiva de lege data en la que aquella se mueve ${ }^{116}$ le imposibilita sacar consecuencias prácticas de ello: Una vez agotadas todas las posibilidades, aun las más generosas, ofrecidas por los criterios de interpretación legal... sólo queda la respetuosa petición al legislador de que modifique la ley. Y ahí acaba la reflexión jurídico penal, porque la creación del derecho no es asunto suyo. De este modo, un esfuerzo de fundamentación del derecho penal tan meritorio como el realizado por este autor cae en la misma trampa que sus predecesores: El jurista ha de presuponer la legitimidad del derecho vigente, y limitarse a buscarle sentido, con mayores o menores pretensiones, dentro de los límites ya dados. Si no se conforma con eso y quiere deslegitimar los fundamentos del derecho vigente habrá de abandonar su profesión y convertirse en un político, oficio poco acreditado académicamente. Si, obstinadamente, persiste en su deseo de seguir siendo jurista y meterse en camisa de once varas, lo mejor que puede hacer es lo que ya conocemos, va-

fines y valores que han de regir la creación y aplicación del derecho penal, ha de quedar ahora fuera de discusión, pues estamos, a mi juicio, ante una confusión muy extendida que precisa de amplio espacio para refutarla.

115 Sobre la postura de Silva aquí recogida, véanse, entre otros pasajes, Silva Sánchez. (1992). 43-48, 52, 98-99, 103-114, 118-122, 133-134, 139-145, 173-174, 193-195. Su planteamiento no parece haber cambiado desde entonces, sino que más bien se ha reforzado, como lo muestra cuando en Silva Sánchez. (1999). 75-82, al sostener la posibilidad de una ciencia del derecho penal supranacional -al menos en el mundo occidental-, que configuraría el derecho penal sobre unos mismos valores compartidos, introduce la salvedad de que en todo caso se habrían de respetar los respectivos derechos positivos.

${ }^{116}$ Y que el propio Silva, a la vez que la reconoce, pone especial interés en destacar que ofrece diferentes grados de vinculación según el ámbito en el que nos movamos, siendo menos estrecho en la Parte general del derecho penal. Véase Silva Sánchez. (1992). 118-122. 
ciar la función de la ley, darle la vuelta mediante la actitud judicializadora que ya hemos visto y criticado en los primeros apartados ${ }^{117}$.

-La segunda de las razones tiene que ver con la siempre aplazada extensión de la racionalidad jurídicopenal a los contenidos susceptibles de ser aportados por el conjunto de las ciencias sociales. Resulta plausible pensar que uno de los motivos fundamentales de que hayan fracasado todos los intentos hasta ahora realizados por insertar en el derecho penal los conocimientos de tales disciplinas, pese a que se han puesto reiteradamente de manifiesto las ventajas que reportarían, tiene que ver con el hecho de que se ha escogido un punto de referencia equivocado, la aplicación del derecho, cuando su pleno desenvolvimiento debe de tener lugar en el marco de la creación del derecho ${ }^{118}$. Dentro de él, es en el ámbito, especialmente, de las racionalidades teleológica y pragmática donde pueden ofrecer toda su utilidad.

5.2. Por lo demás, ya hemos tenido ocasión de constatar cómo el derecho penal mantiene unas capacidades de racionalización de la ley mayores que otros sectores jurídicos ${ }^{119}$, y su habituación al uso de estructuras racionales rígidas y refinadas en la aplicación del derecho, como la de la teoría jurídica del delito, le coloca en una situación aventajada para fomentar estructuras categoriales de naturaleza similar en la creación del derecho ${ }^{120}$.

No deberíamos, sin embargo, caer en el error de trasponer sin más la teoría jurídica del delito al ámbito de la racionalidad legislativa. El conjunto de principios que la sustentan deberá ser analizado en un nivel u otro de racionalidad, pero ello sucederá en el contexto de la racionalidad correspondiente. La racionalidad legislativa no se agota en el aseguramiento de un sistema de responsabilidad socialmente convincente, debiendo atender igualmente, cuando menos, a una correcta determinación de los objetos de tutela y del sistema de sanciones. Tampoco, por mucha coincidencia que se produzca, es lo mismo establecer los criterios que en un momento cultural e histórico determinado han de regir la exigencia de responsabilidad por los actos de uno, que plasmar tales criterios de manera operativa en el marco de un proceso judicial encargado de determinar tal responsabilidad en un caso concreto.

Fácil de apreciar es, por otra parte, la superposición parcial de contenidos que se produce entre los niveles de racionalidad legislativa y los criterios de interpretación de las leyes ${ }^{121}$. Así, la racionalidad lingüística se apro-

\footnotetext{
117 Véase en especial apartados 1 a 3.

${ }^{118}$ Llaman la atención sobre su importancia en este ámbito, Hassemer-Steinert-Treiber. 2.

119 Véase supra apartado 1 in fine

${ }^{120}$ Siempre que venza algunas inercias, como el efecto secante de la teoría jurídica del delito aludido en apartado 1 in fine. Véase ya una propuesta en ese sentido en Díez Ripollés.

${ }^{121}$ Véase Atienza. 97-99, quien establece una vinculación más estrecha que la que yo formulo.
} (1997). 14-15. 
ximaría al criterio gramatical, la racionalidad jurídicoformal al criterio sistemático, la racionalidad pragmática, en alguna medida, al criterio histórico, y la racionalidad teleológica al criterio teleológico-valorativo. Aún podría decirse que de algún modo la racionalidad ética tendría algo que ver con el criterio de interpretación conforme a la constitución. Este solapamiento no ha de extrañar, pues si a través de los diversos niveles de racionalidad legislativa se deciden los contenidos de la ley, es justamente la determinación de esos contenidos lo que persiguen los criterios de interpretación. Por otro lado, tal coincidencia parcial refuerza la consistencia del derecho penal como instrumento de control social, al dotarle de un sustrato epistemológico equivalente en diferentes niveles operacionales, asegurando la continuidad de una misma estructura de racionalidad en la creación y en la aplicación del derecho.

De ahí que se haya de fomentar tal vinculación, aunque sin buscar paralelismos rígidos sospechosos. Entre otros motivos porque, dado el nivel aún rudimentario de la teoría y técnica legislativas, está aún pendiente de una convincente disipación la duda de si no estaremos ante una coincidencia sólo superficial, deliberadamente buscada para ocultar las carencias conceptuales de la racionalidad legislativa mediante su acercamiento a modelos ya conocidos y consolidados en otros ámbitos del derecho penal. Es la idea de coordinación, más que de identificación, la que debería regir las relaciones entre las racionalidades de creación y aplicación del derecho ${ }^{122}$.

5.3. Ciertamente los intentos de descomposición de los diversos niveles de la racionalidad legislativa penal serán inicialmente provisionales e incompletos. Ni siquiera estarán probablemente en condiciones de mantener una cierta proporcionalidad en la atención prestada a los contenidos de cada una de las racionalidades, centrándose más bien en aspectos de algunas de ellas de especial interés. Pero si logran distribuir de manera coherente principios y criterios entre las diversas racionalidades, y enriquecerlas progresivamente, ya se habrá realizado una labor, modesta, pero trascendente.

A mi juicio, y sin perjuicio de su denominación como principio, regla o criterio, los materiales que se han de introducir en las sucesivas racionalidades pueden responder a alguna de las caracterizaciones siguientes: Por un lado, a partir de los principios estructurales de primer grado y, en menor medida, del criterio democrático, identificados y alojados en la racionalidad ética, se han de descomponer una serie de principios estructurales de segundo grado que desenvuelven su actividad dentro de los presupuestos específicos de alguna de las subsiguientes racionalidades, a cuyas pautas

122 Estima que una racionalidad legislativa desarrollada terminaría condicionando la racionalidad judicial de forma decisiva, Calsamiglia. 177. 
éticopolíticas, de efectividad y eficacia, de consistencia o de comunicabilidad sirven.

Por otro lado, existen unos principios a los que podemos denominar coyunturales, los cuales ya no constituirían un desarrollo de los principios estructurales de primer grado en cualquiera de las racionalidades subsiguientes, sino que, sin contradecir a éstos, expandirían las exigencias de racionalidad del nivel en el que se localizan en un plano más restringido y contingente, muy vinculado a las cambiantes realidades sociales o jurídicas, y sin un último fundamento ético. Ello explicaría igualmente que su relevancia se confine al ámbito de la creación del derecho, sin que tengan reflejo operativo en la aplicación de éste por la jurisdicción o la ejecución penales, a diferencia de lo que será normal en los principios estructurales ${ }^{123}$.

\section{Bibliografía citada}

Abajo Quintana, J. (1994). «Directrices sobre la forma y estructura de los anteproyectos de ley: Antecedentes y finalidad». En Corona-Pau-Tudela. «La técnica legislativa a debate». Tecnos.

Aguiló Regla, J. (2000). «Técnica legislativa y documentación automática de legislación». En Carbonell-Pedroza. «Elementos de técnica legislativa». UNAM.

AMElung, K. (1980). «Strafrechtswissenschaft und Strafgesetzgebung». ZStW.

Atienza, M. (1997). «Contribución a una teoría de la legislación». Civitas.

BECK, U. (1998). «La sociedad del riesgo». Paidós

Calsamiglia, A. (1993). «¿Debe ser la moral el único criterio para legislar?». Doxa. 13.

Cerezo Mir, J. (1996). «Curso de derecho penal español. Parte general. I. Introducción». $5^{\text {a }}$ edición. Tecnos.

Corona Ferrero, J.M. (1994). «En torno al concepto de técnica legislativa». En Corona-Pau-Tudela. «La técnica legislativa a debate». Tecnos.

Cuerda Riezu, A. (1991). «El legislador y el derecho penal». Ed. Centro de estudios R. Areces.

DíEz RiPOLLÉS, J.L. (1988). Recensión a W.Perron. «Rechtfertigung und Entschuldigung im deutschen und spanischen Recht». ADPCP.

- (1991). «La categoría de la antijuricidad en derecho penal». ADPCP.

- (1997). «El bien jurídico protegido en un derecho penal garantista». Jueces para la democracia. $n^{\circ} 30$.

- (2001). «El derecho penal simbólico y los efectos de la pena». Actualidad penal. $\mathrm{n}^{\mathrm{o}} 1$.

- (2002). «Un modelo dinámico de legislación penal», en «La ciencia del derecho penal ante el nuevo siglo. Libro homenaje al Profesor Cerezo Mir». Díez Ripollés-Romeo Casabona-Gracia Martín-Higuera Guimerá eds. Tecnos. En prensa.

FERRAJOLI, L. (1990). «Diritto e ragione». Editori Laterza.

${ }^{123}$ Véase una primera formulación de estos principios en Díez Ripollés. (1997). 12-13, 15-17. 
Giménez Alcover, P. (1993). «El derecho en la teoría de la sociedad de Niklas Luhmann». J.M.Bosch editor.

GarCía PÉreZ, O. (1997). «La punibilidad en el derecho penal». Aranzadi editorial. Habermas, J. (1994). «Faktizität und Geltung». Suhrkamp. $4^{a}$ edic.

HAFFKE, B. (2001). «Die Legitimation des staatlichen Strafrechts zwischen Effizienz, Freiheitsverbürgung und Symbolik», en «Festschrift für Claus Roxin». Walter de Gruyter.

HASSEMER-Steinert-Treiber. (1978). «Soziale Reaktion auf Abweichung und Kriminalisierung durch den Gesetzgeber». En «Sozialwissenchaften im Studium des Rechts. Bd. III. Strafrecht». Verlag C.H.Beck.

Hierro, L. (1996). «El imperio de la ley y la crisis de la ley». Doxa. 19.

LARRAURI PIJOAN, E. (1998). «Control del delito y castigo en EEUU: una introducción para el lector español». En v. Hirsch. «Censurar y castigar». Trotta.

- (2001). «Aportación de las ciencias sociales a la elaboración de reformas en la legislación penal». En «Los problemas de la investigación empírica en criminología». Díez Ripollés-Cerezo Domínguez eds. Tirant-IAIC.

Luhmann (1995). «Das Recht der Gesellschaft». Suhrkamp.

Marcilla Córdoba, G. (2000). «Sobre la necesidad de una nueva ciencia de la legislación». En Carbonell-Pedroza. «Elementos de técnica legislativa». UNAM.

MARTINEZ-BujÁN, C. (2002). «Algunas reflexiones sobre la moderna teoría del «Big Crunch» en la selección de bienes jurídico-penales (especial referencia al ámbito económico)», en «La ciencia del derecho penal ante el nuevo siglo. Libro homenaje al Profesor Cerezo Mir». Díez Ripollés-Romeo Casabona-Gracia Martín-Higuera Guimerá eds. Tecnos. En prensa.

Mir PuIG, S. (1982). «Función de la pena y teoría del delito en el estado social y democrático de derecho». $2^{\mathrm{a}}$ edic. Bosch casa editorial.

Palazzo, F. (1997). «Scienza penale e produzione legislativa: Paradossi e contradizioni di un rapporto problematico». Rivista italiana di diritto e procedura penale.

PRIETo DEL Pino, A.M. (2002). «El abuso de información privilegiada en el mercado de valores». Tesis doctoral inédita.

Prieto SANChís, L. (1998). «Ley, principios, derechos». Dykinson.

RodríGUEZ MONDRAGÓn, R. (2000). «El proceso de producción legislativa, un procedimiento de diseño institucional». En Carbonell-Pedroza. «Elementos de técnica legislativa». UNAM.

SAINZ Moreno, F. (1994). «Técnica normativa: Visión unitaria de una materia plural». En Corona-Pau-Tudela. «La técnica legislativa a debate». Tecnos.

RoxIN, C. (1972). «Política criminal y sistema del derecho penal». Bosch casa editorial.

SAlvador Coderch, P. (1982). «Dogmática jurídica y teoría de la legislación». Cuadernos de la Facultad de Derecho de Palma de Mallorca. 3-82.

- (1986). «Introducción». En «La forma de las leyes». Bosch casa editorial.

- (1989). «Elementos para la definición de un programa de técnica legislativa». En «Curso de técnica legislativa. Gretel». Centro de Estudios Constitucionales.

SchünEmanN, B. (1996). «Consideraciones críticas sobre la situación espiritual de la ciencia jurídicopenal alemana». Universidad Externado de Colombia. 
SiLva SÁncheZ, J. (1997). «Nuevas tendencias políticocriminales y actividad jurisprudencial del tribunal supremo». En Romeo Casabona ed. «Dogmática penal, política criminal y criminología en evolución». Comares.

- (1992). «Aproximación al derecho penal contemporáneo». J.M.Bosch editor.

- (1999). «La expansión del derecho penal». Civitas.

Soto NAvARro, S. (2002). «Los bienes jurídicos colectivos. Legitimidad y bases metodológicas para su concreción». Tesis doctoral inédita.

Tudela Aranda, J. (1994). «La legitimación competencial de las leyes y la técnica normativa». En Corona-Pau-Tudela. «La técnica legislativa a debate». Tecnos.

VALLE MuÑIZ, J.M. (1994). «El elemento subjetivo de justificación y la graduación del injusto penal». PPU.

ZAPATERo Gómez, V. (1994). «De la jurisprudencia a la legislación». Doxa. 15-16.

ZimRING-Hawkins-Kamin (2001). «Punishment and Democracy. Three Strikes and you're out in California». Oxford University Press. 
$\triangle \quad$ DOXA 24 (2001) 